\title{
ELABORACIÓN DE UN ARPÓN MAGDALENIENSE: HUELLAS DE FABRICACIÓN Y USO A TRAVÉS DE LA ARQUEOLOGÍA EXPERIMENTAL ${ }^{27}$
}

\author{
Manufacture of a Magdalenian harpoon: traces of the process and \\ use through Experimental Archaeology
}

Beatriz Ugarte Villalba;Error! Marcador no definido. ${ }^{28}$

\section{Resumen}

La finalidad de este trabajo es documentar las marcas presentes en un arpón magdaleniense tras su fabricación a través de la Arqueología Experimental, para poder distinguirlas de las huellas de uso en arpones arqueológicos. Además, pretendemos generar marcas del cordaje del enmangue en el asta, tal y como se han hallado en arpones como los de El Horno (Ramales de la Victoria, Cantabria).

Palabras clave: arpón, Magdaleniense Superior, fabricación, traceología, Arqueología experimental.

\begin{abstract}
The purpose of this paper is documenting the traces found in a Magdalenian harpoon after its manufacture through Experimental Archaeology, in order to differentiate them from the traces of use in archaeological harpoons. In addition, we intend to generate traces of the string in the horn as they have been found in harpoons such as those of El Horno (Ramales de la Victoria, Cantabria).
\end{abstract}

Keywords: harpoon, Upper Magdalenian, manufacture, traceology, Experimental Archaeology.

\section{INTRODUCCIÓN}

Atendiendo a la definición de Javier Baena (1997: 3), la Arqueología Experimental es "ante todo un modelo de contrastación de hipótesis a través de la experimentación que de forma rigurosa admita la validez, para fases de la Prehistoria, de un proceso técnico desarrollado en la actualidad". De manera que, previo al trabajo en sí, debemos realizarnos algunas preguntas y documentarnos acerca de qué elementos se utilizaban para elaborar determinado útil, en la fase cultural que nos corresponda de la Prehistoria. En nuestro caso, hemos de realizar un arpón de tipo magdaleniense sobre asta de ciervo para cuya fabricación he necesitado estudiar diferentes arpones arqueológicos procedentes de yacimientos situados a lo largo de la cornisa cantábrica, para definir las características que debía tener. La Arqueología Experimental no solo es un procedimiento o una metodología a seguir para obtener un objeto o útil prehistórico, sino que también es la forma a través de la cual podemos acercarnos al comportamiento de nuestros

\footnotetext{
${ }^{27}$ Recibido: 28/11/2018. Aceptado: 03/12/2018. http://doi.org/10.15366/baexuam2018-19.13.006

28 Universidad Autónoma de Madrid. ORCID: 0000-0002-0811-266X. E-mail: beatriz.ugarte@estudiante.uam.es
} 
antepasados, a la manera de tallar, la posibilidades o limitaciones de algunas acciones, etc. Ellos aprovechaban todo tipo de materias presentes en el medio natural que, al ser utilizadas por nosotros y observar que dan resultado, nos asombran por la cantidad de información que tenían y que muchas veces se ignora.

La prof. Carmen Gutiérrez explicó que esta Arqueología Experimental se apoya en un método científico cuyo objetivo es aportar conocimiento. La experiencia también aporta conocimiento, pero sobre todo sirve para formarse (autodidáctico). El método experimental elige y trata las condiciones en que se producen un fenómeno para observar sus consecuencias. La función principal es el contraste de hipótesis mediante el control de variables (Gutiérrez, 2017):

- Variables dependientes: son los fenómenos resultantes de la interacción de las variables independientes.

- Variables independientes: son los elementos que intervienen en la experimentación.

Los diferentes puntos implicados en el experimento y desarrollo del proceso experimental son: definición del marco crono-geográfico, definición del marco material y definición del marco técnico. Con respecto a la documentación debemos recopilar todos los datos posibles, desde los datos arqueológicos (fauna...), etnoarqueológicos, hasta los geoarqueológicos (Gutiérrez, 2017).

En este trabajo opté por llevar a cabo una experimentación intuitiva, es decir, trabajar como se supone que lo hicieron los hombres prehistóricos. El problema era ejecutar un gesto que desconocemos y que se ha reconstruido a partir de las huellas dejadas en materiales arqueológicos que han sufrido todo tipo de procesos al depositarse en los suelos durante miles de años (procesos postdeposicionales). Entonces desde un primer momento el experimentador se presenta ante el proceso experimental con una carga conceptual y metodológica concreta (Gutiérrez, 2017). Se necesita cierto nivel de habilidad mecánica y destreza que es fundamental porque influye en los resultados. Por eso muchas veces repetir los experimentos eleva a un rango mayor los resultados. A veces tenemos algunas alternativas a la experimentación como, por ejemplo, para observar la eficacia, en lugar de elaborar el útil manualmente podemos utilizar tecnología actual acelerando los procesos.

Con respecto a la traceología, es una parte importante del trabajo porque gracias a ella podré enmarcar el objetivo del trabajo observando las estrías generadas en el arpón. La traceología, cuyos padres son Semenov y Keeley, comenzó como un método basado en la experimentación donde la presencia de una serie de huellas características nos permite estudiar el material arqueológico, aunque éste en ocasiones nos remita de nuevo a una experimentación (Gutiérrez, 2017).

\section{MARCO CRONO-GEOGRÁFICO Y REGISTRO ARQUEOLÓGICO}

El periodo Magdaleniense (18.000-10.000 B.P.) se caracteriza sobre todo por una complejización de la industria ósea, pero con novedades en la industria lítica. Es característica la pervivencia de raspadores o raederas. Además, se tendió a la microlitización, es decir, muchas láminas empleadas en instrumentos con mango. Sobre la industria ósea siguieron apareciendo las azagayas de bisel y aparecieron los arpones 
con una o dos hileras de dientes trabajados sobre todo en asta. Destacan sobre todo las expresiones de arte magdalenienses.

"La adición de dientes a las puntas elaboradas sobre materias duras animales fue una innovación de gran calado de estas armas, que supuso un cambio importante en la concepción de la captura de las presas. Ha podido comprobarse experimentalmente (Pokines y Krupa, 1997) que, gracias al diseño de los dientes, las puntas no se desprenden fácilmente de las presas heridas" (Fano, Clemente y Rivero, 2013).

Durante este periodo y a lo largo del Paleolítico Superior en la región cantábrica, la pesca tanto en ríos como en estuarios se convirtió en una importante fuente de alimentación, aunque de manera complementaria a la caza. "La cantidad de restos de pescados correspondientes a capas del MSFC (Magdaleniense Superior Final Cantábrico), sugiere una aceleración del proceso de incremento de pesca" (González, 1989: 174). La aparición y formalización de los arpones es testimonio de ello. El mismo autor apunta que de esta manera no se puede ignorar la aparición de representaciones parietales de peces enmarcadas en conjuntos del estilo IV reciente (salmones en Ekain y Altxerri, dos gallos en Altxerri y posiblemente un lenguado en Ekain). Además, esto concuerda con los restos de salmones y truchas hallados en yacimientos no costeros, y con los restos de reos, doradas, sabias, erlas, platijas, gallos y lenguados en yacimientos costeros.

Dentro del Magdaleniense reciente -época comprendida entre la aparición de los primeros arpones y la generalización del tipo aziliense- encontraríamos dos épocas consecutivas: el Magdaleniense medio y el Magdaleniense superior-final. La aparición de los protoarpones no fue anterior al 14.500-14.000 B.P. El tipo aziliense comenzaría en torno al 10.300 B.P. aproximadamente. El Magdaleniense medio sería el asociado a los protoarpones hasta el 13.500-13.000 B.P. cuando comenzaría el Magdaleniense superiorfinal. Tampoco se descarta la fabricación sincrónica de apones y protoarpones (González, 1986). "El Magdaleniense Medio coincidiría con la fase climática VI, mientras que en la

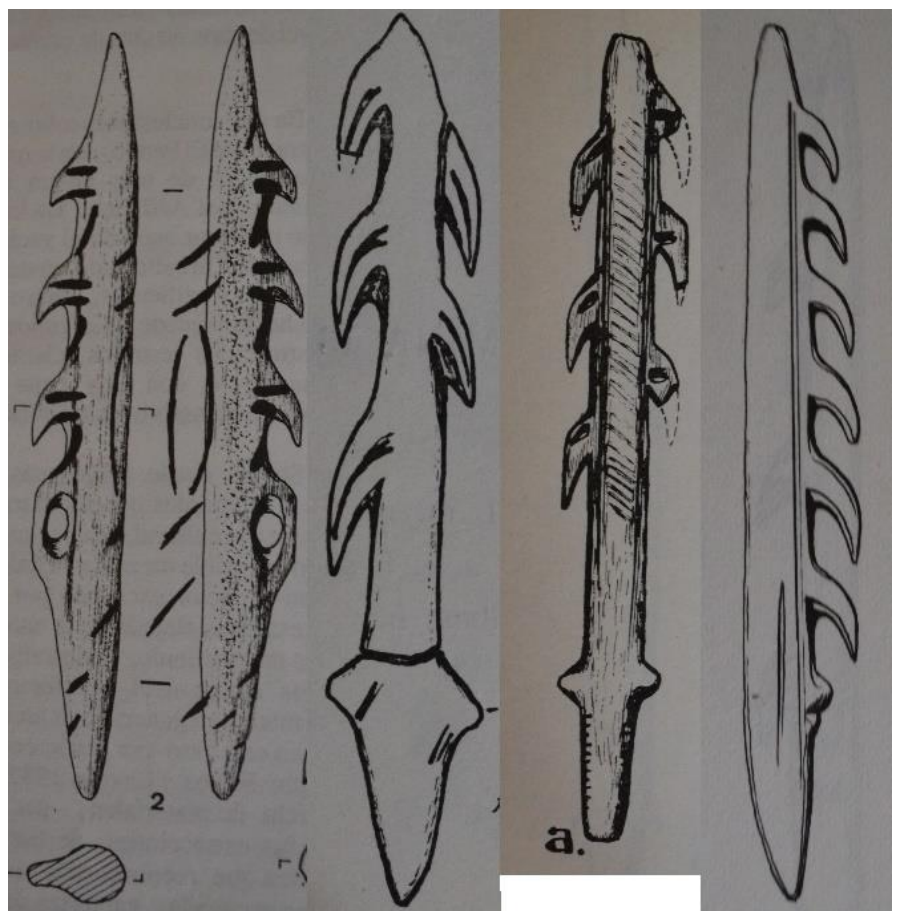

Figura 1. Arpones hallados (de izquierda a derecha) en las cuevas de El Pendo, Santimamiñe, Aitzbitarte IV y La Madeleine (González, 1989; Barandiarán, 1967 y Julien, 1982). 

experimental

transición a la VII (o Dryas II) aparecerían ya los arpones formalizados" (González, 1986: 873). En este momento es cuando también aumenta la producción de arpones frente a la de varillas, bastones perforados, espátulas o azagayas.

El arpón principal sobre el que me basé para realizar el protagonista de este trabajo es uno procedente de la cueva de El Pendo (Cantabria), aunque observando muchos otros, también pude estudiar ciertas características en otros tres más procedentes de la cueva de Santimamiñe, de la cueva de Aitzbitrte IV y de La Madeleine (Fig. 1).

La cueva de El Pendo está situada en el término de Escobedo (Camargo), al suroeste de Santander. El que primero la documentó científicamente fue Marcelino Sanz de Sautuola en 1878. Se única entrada es de orientación norte y debido a sus grandes dimensiones permite que el sol penetre muy al interior en determinados meses del año (Carvallo, 1960). En este yacimiento, sin lugar a dudas, destaca la industria ósea -incluyendo en ella piezas realizadas en hueso, asta, marfil, dientes y conchas.

Abundan los arpones, algunos de ellos en un muy bien estado de conservación. Carvallo (1960: 53) expone que "dentro de la morfología general cantábrica, los hay muy variados, y algunos de una esbeltez incomparable". No solamente se elaboran mediante perfectas técnicas, sino que además expresan un importante gusto artístico. La mayoría son de sección cilíndrica y orificio lateral alineado en serie con los anzuelos. Por otro lado, encontramos tanto de hilera única como de hilera doble. En resumen, muestran las características propias del Magdaleniense cantábrico. También algunos de ellos poseen grabados, como el que muestra la cabeza y el cuello de un équido al galope (Fig. 2). Sin embargo, piezas procedentes del mismo nivel parecen cambiar su morfología a una más aplanada que derivaría a los tipos azilienses. El orificio, además, se sitúa en el centro de la sección y carecen de pulimento. Por todo esto, Carvallo los enmarcó dentro de un periodo diferente, aunque fueron hallados en el nivel magdaleniense.

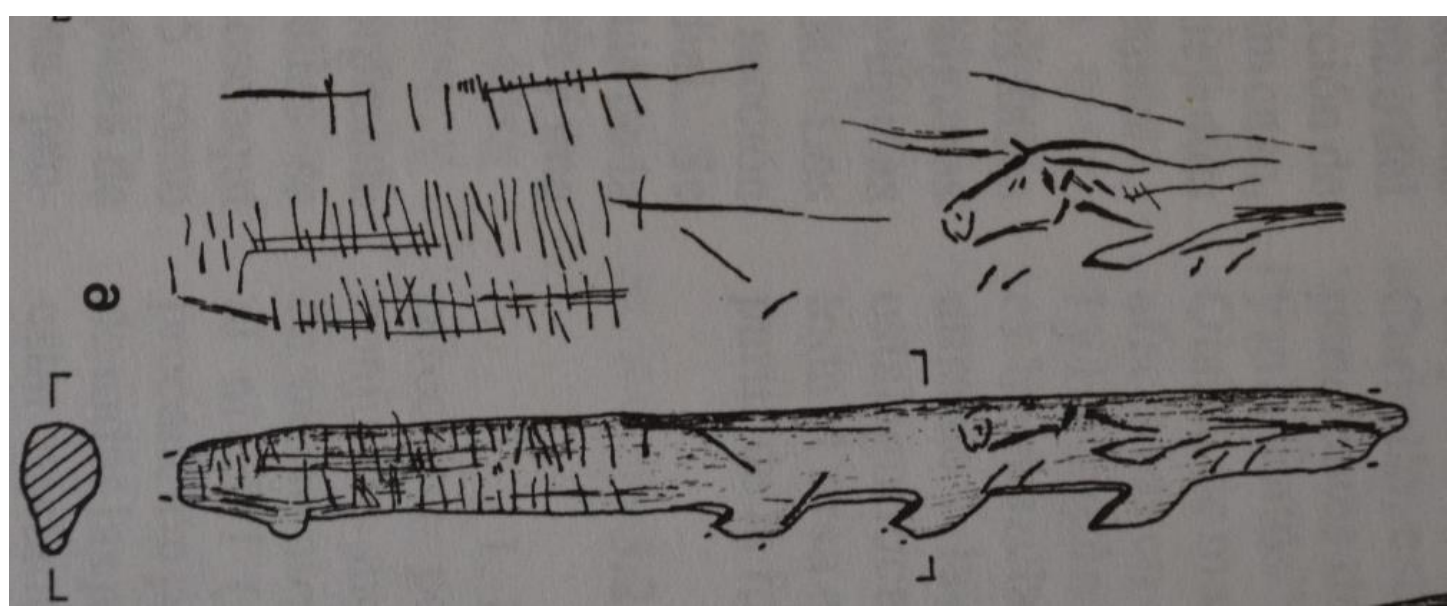

Figura 2. Dibujo de un arpón magdaleniense de la cueva de El Pendo que presenta un característico grabado de un équido al galope (González, 1989).

Los arpones del Magdaleniense $\mathrm{V}$ ya eran importantes fósiles directores como bien indica Barandiarán (1967). "Suelen tener una sola hilera de dientes (pequeños, muy juntos y numerosos al principio; largos, algo curvados y en menor número, después) y, en ejemplares ya tardíos, comienzan a aparecer los dientes al otro costado" (Barandiarán, 1967: 258). 


\section{MATERIALES EMPLEADOS}

Con respecto a las materias primas y materiales empleados para llevar a cabo el presente trabajo, en primer lugar, destaca el asta (Fig. 3). Atendiendo a Barandiarán (1967) es la materia más empleada, posiblemente, en la industria Paleolítica. Las astas son unas formaciones de tejido conjuntivo, duramente calcificadas, que crecen a partir de un pedicelo óseo, en bóvidos, cápridos y cérvidos (son éstos exclusivos de los machos a excepción del reno cuyas hembras también las poseen) cayendo y renovándose todos los años. Las astas de los ciervos, debido a su dureza y resistencia han sido muy utilizadas en la fabricación del utillaje óseo para caza y pesca (azagayas, arpones, alisadores, raspadores, propulsores, bastones de mando, varillas, cinceles, espátulas, etc).

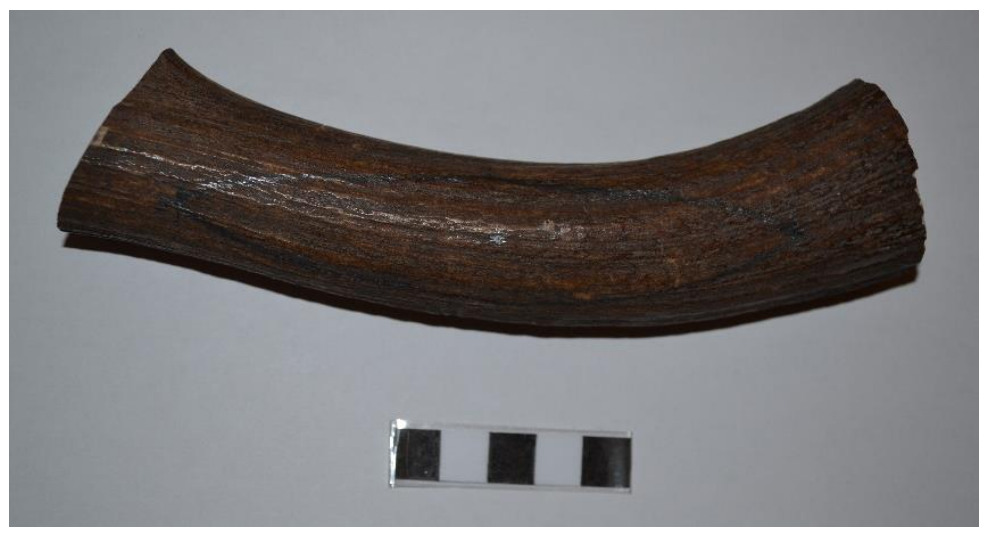

Figura 3. Fragmento de un asta de ciervo seleccionada para extraer de ella el arpón.

El asta está formada por la parte cortical compacta y resistente (tejido muy calcificado) que varía en su grosor (entre 7 y $9 \mathrm{~mm}$ en la mayoría de los cérvidos) y otra parte axial de estructura esponjosa. Por lo que los arpones se extraían de varillas de la zona cortical.

En el trabajo de Villaverde y Román (2005) se estudiaron una serie de arpones cuyas descripciones me fueron de gran utilidad para definir las características del arpón experimental a realizar.

- Pieza 1. Fabricado sobre hueso. Una hilera de dientes. Longitud 3,54 cm, achura $0,53 \mathrm{~cm}$ y grosor $0,53 \mathrm{~cm}$. Sección oval. Fragmento. "Los dientes están decorados con una línea incisa, bastante marcada y paralela al eje del diente” (Villaverde y Román, 2005).

- Pieza 2. Fabricado sobre asta de ciervo. Una hilera de dientes. Longitud 2,91 $\mathrm{cm}$. Sección aplanada. No posee decoración. Fragmento.

- Pieza 3. Arpón completo. Fabricado sobre asta de ciervo. Una hilera de dientes. Longitud 7,32 cm, anchura $1,24 \mathrm{~cm}$ y grosor $0,54 \mathrm{~cm}$. Sección aplanada. Su punta es convergente convexa y su zona de impacto lineal, mientras que el extremo proximal parece ser redondeado. "La base carece de modificaciones relacionadas con la sujeción” (Villaverde y Román, 2005). El arpón no presenta decoración, aunque sí unas marcas longitudinales en el adelgazamiento de la zona de los dientes, sin duda producidas en el proceso de su elaboración.

- Pieza 4. Fabricado sobre hueso. Una hilera de dientes. Longitud 2,69 cm y anchura $0,75 \mathrm{~cm}$. Sección oval. La zona de impacto es puntiforme. 
- Pieza 5. Fabricado en hueso. Una hilera de dientes. Longitud 5,82 cm, anchura $0,83 \mathrm{~cm}$ y grosor $0,62 \mathrm{~cm}$. Sección oval, pero punta aplanada.

- Pieza 6. Fabricado en asta de ciervo. Una hilera de dientes. Longitud 2,89 cm, anchura $1,11 \mathrm{~cm}$ y grosor $0,55 \mathrm{~cm}$. Fragmento.

- Pieza 7. Arpón completo. Fabricado sobre asta de ciervo. Una hilera de dientes. Longitud $9,73 \mathrm{~cm}$, anchura $1,06 \mathrm{~cm}$ y grosor $0,85 \mathrm{~cm}$. Sección cuadrangular excepto en el extremo distal que es oval. "Como elementos de sujeción cuenta con un adelgazamiento en forma de doble bisel" (Villaverde y Román, 2005). Los dientes se separan del fuste.

- Pieza 8. Fabricado sobre asta de ciervo. Una hilera de dientes. Longitud 8,46 $\mathrm{cm}$, anchura $1,03 \mathrm{~cm}$ y grosor $0,61 \mathrm{~cm}$. Sección cuadrangular. La base es redondeada sin ningún elemento de sujeción.

- Pieza 9. Fabricado en asta de ciervo. Una hilera de dientes. Longitud 5,32 cm, anchura $0,83 \mathrm{~cm}$ y grosor $0,51 \mathrm{~cm}$. Sección circular. Punta de bordes convergentes convexos. Zona de impacto puntiforme.

- Pieza 10. Fabricado en asta de ciervo. Una hilera de dientes. Longitud 1,58 $\mathrm{cm}$, anchura $0,84 \mathrm{~cm}$ y grosor $0,43 \mathrm{~cm}$. Sección oval. Fragmento.

En general no superan los $10 \mathrm{~cm}$. La base o módulo de los dientes respecto al fuste es destacada y esa zona es de sección aplanada.

De acuerdo a estos datos y a los arpones previamente señalados, elaboré un boceto (Fig. 4) con medidas: $11,5 \mathrm{~cm}$ de largo por $2 \mathrm{~cm}$ de ancho para la matriz del asta, a partir de la cual extraer el arpón.

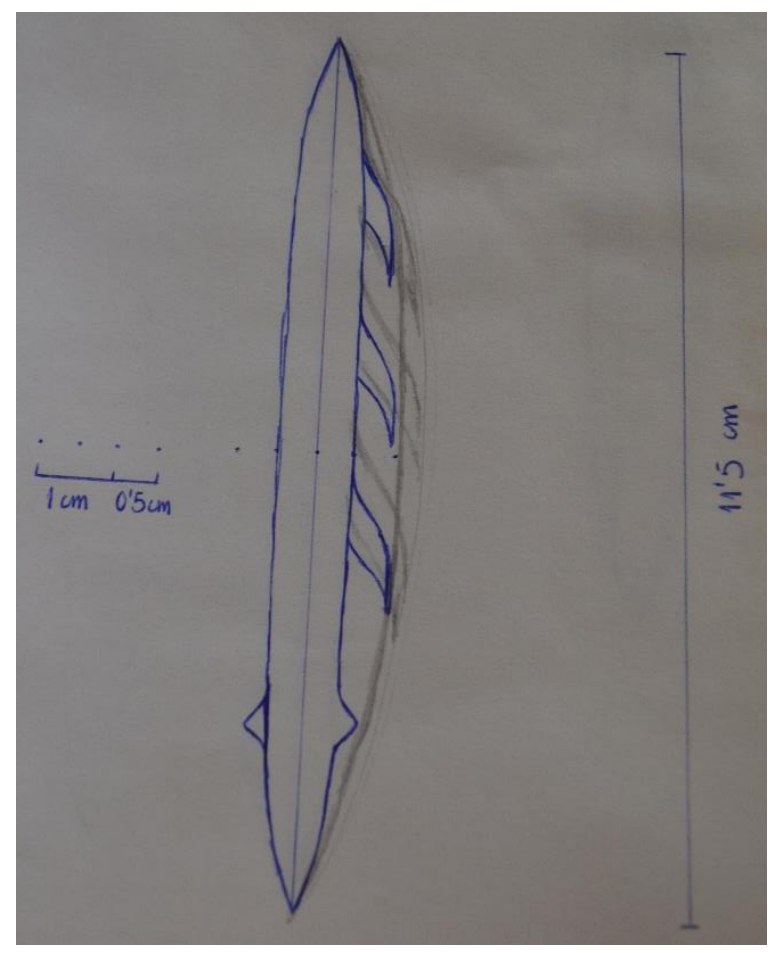

Figura 4. Boceto del arpón a realizar.

Otros materiales que utilicé fueron: 
- buriles de sílex (Fig. 5), los más planos posibles para poder incidir en el asta de forma longitudinal.

- Lascas de sílex para la extracción de la matriz.

- Taco de madera de boj para la extracción de la matriz.

- Piedra arenisca para el pulimento del arpón.

- Segueta para acelerar el proceso de la realización de los dientes.

- Percutor de boj para deshacer un tendón de ciervo del que extraer hebras para confeccionar una pequeña cuerda.

- Tendón de ciervo.

- Tripa animal para el enmangado del arpón.

- Vástago cilíndrico de $2 \mathrm{~m}$ de madera de pino.

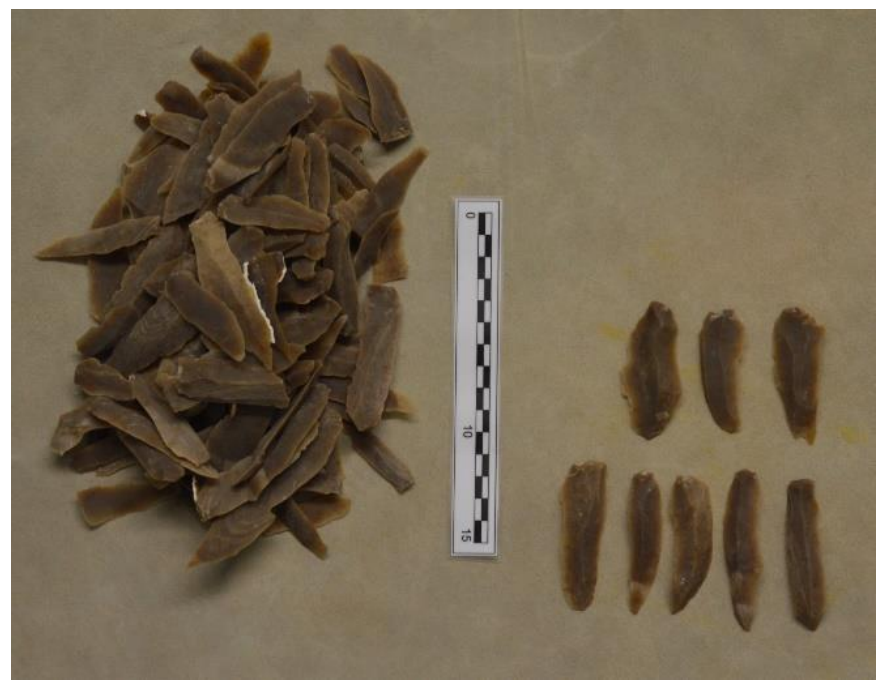

Figura 5. A la derecha: buriles de sílex seleccionados para extraer la matriz del arpón.

Por lo tanto, siguiendo el esquema de cualquier trabajo de Arqueología experimental, establecí las variables dependientes y las independientes manejadas durante el proceso:

- Variables dependientes: Morfología del arpón, materia del arpón (asta), tipo de asta (seca o fresca), tiempo de fabricación, tiempo de uso o número de veces usado, acción (ej: pulido longitudinal o transversal),

- Independientes: marcas de fabricación y huellas de uso (estrías, residuos, pulimento).

\section{PROCESO DE FABRICACIÓN Y ENMANGUE}

Gracias a un audiovisual del Museo Arqueológico de Asturias en el cual se podía observar brevemente la fabricación de un arpón aziliense, pude extrapolar los datos para la elaboración del arpón que nos ocupa. En primer lugar, dibujé con un lápiz la matriz que quería extraer del arpón con una longitud de $11,5 \mathrm{~cm}$ y una anchura de $2 \mathrm{~cm}$. Siguiendo esa línea -y habiendo, previamente, introducido en un recipiente con agua durante 18 horas el asta- realicé un corte longitudinal con los buriles mediante la técnica "PushPlough" (Fig. 6) que explica Barandiarán (1967), es decir, deslicé el filo del buril repetidamente hasta conseguir la profundidad del surco necesaria $(2 \mathrm{~cm}$ aproximadamente) (Fig. 7) hasta llegar al tejido esponjoso del asta. Durante todo este 
B. Ugarte

Elaboración de un arpón magdaleniense: huellas de fabricación y uso a través de la arqueología experimental

proceso y para el pulimento estuve humedeciendo el asta bajo el grifo para que me fuese más fácil trabajar la materia. La duración de la incisión con los buriles en el asta fue de 7 horas 15 minutos.

Para la extracción planteamos encajar lascas de sílex en ambos surcos (Fig. 8) para aplicarles presión con el golpeo de un percutor, pero lo que generamos fue pequeños fragmentos de lascas que se clavaban en el fondo del surco y nos impedían continuar presionando. Dejado a un lado este procedimiento, el prof. Javier Baena me planteó la opción de realizar un apalancado con un taco de madera de boj (Fig. 9) que al ser golpeado por el percutor varias veces en varios puntos haría saltar la matriz. Lo pusimos en práctica, y así fue como pudimos sin ningún tipo de problema extraer la base sobre la que hacer el arpón (Figs. 10 y 11).

Tras esto, comencé a pulir sobre una piedra arenisca con arena (Fig. 12) y agua ambas caras del arpón para eliminar tanto la parte amarronada de la cortical como el tejido esponjoso de la cara interior. Este proceso me llevó 4 horas y 30 minutos ya que la eliminación del tejido esponjoso fue dificultosa.

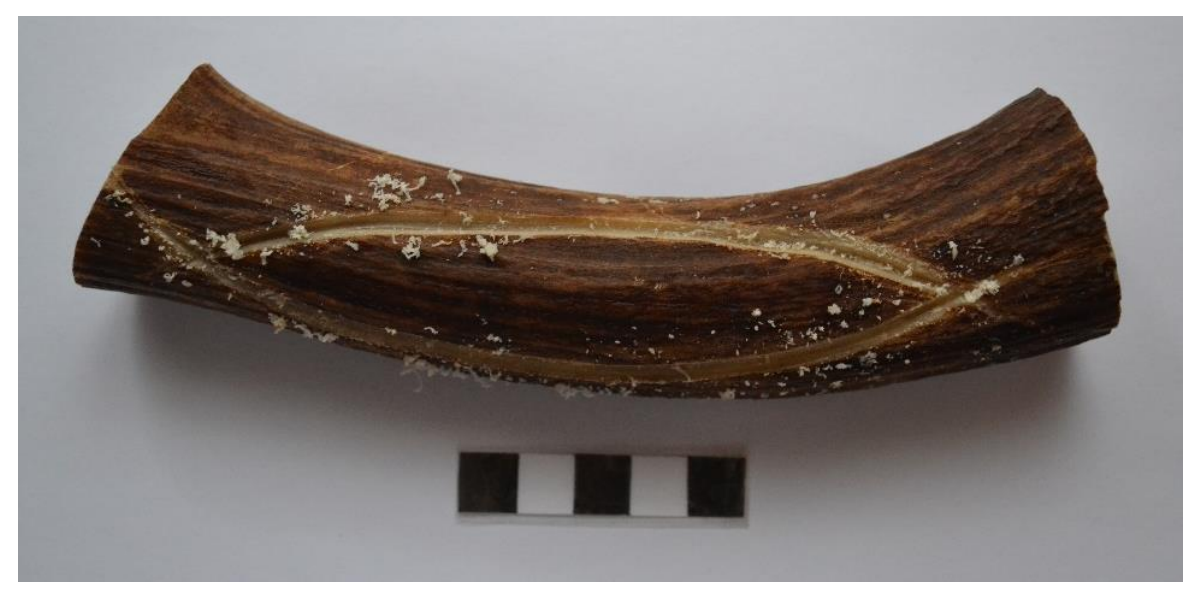

Figura 6. Incisión con buril en el asta de ciervo formando la matriz que extraer para el

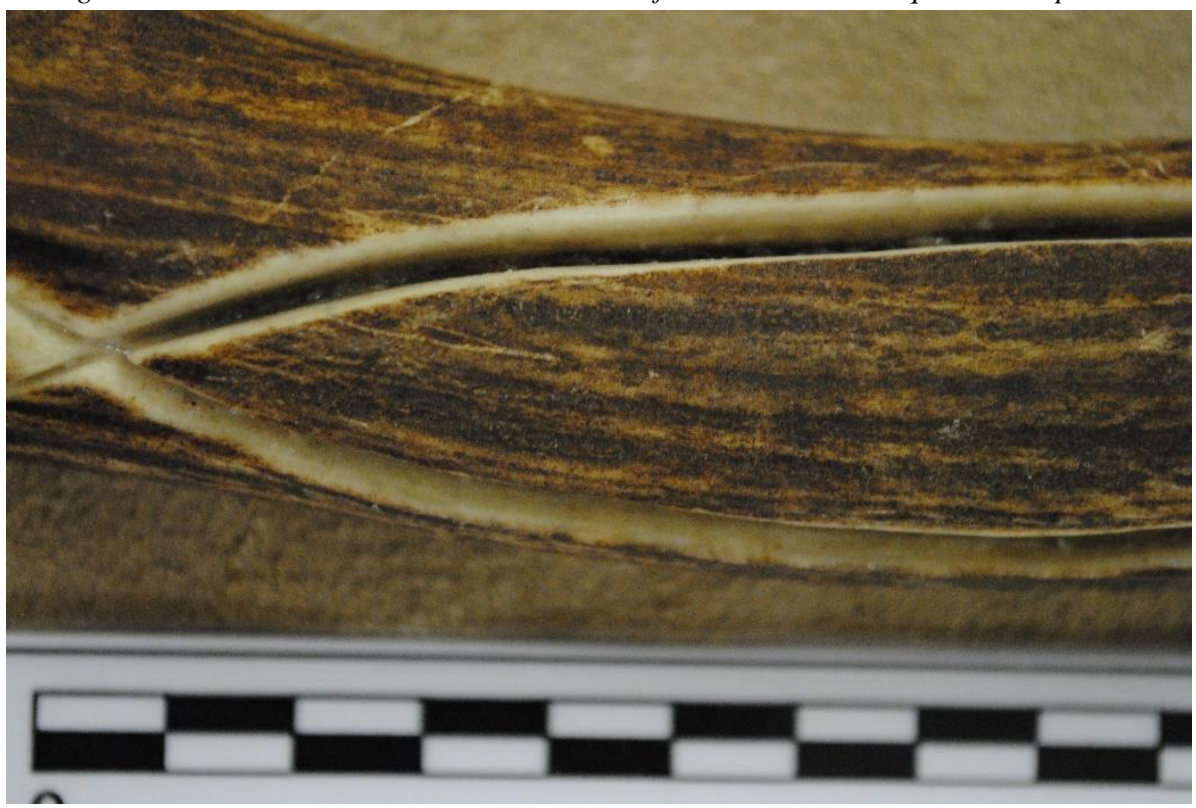

Figura 7. Surcos realizados antes del apalancamiento para la extracción de la matriz. 


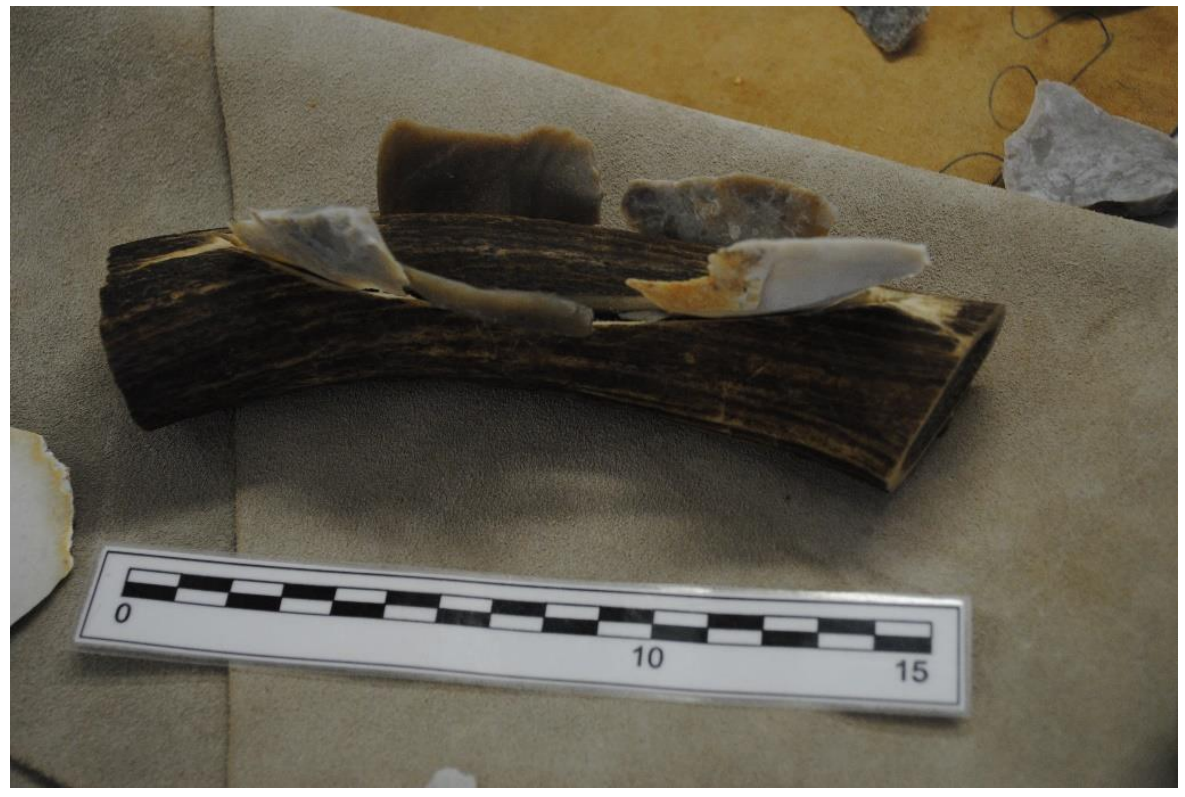

Figura 8. Lascas introducidas en los surcos del asta en el proceso de extracción.

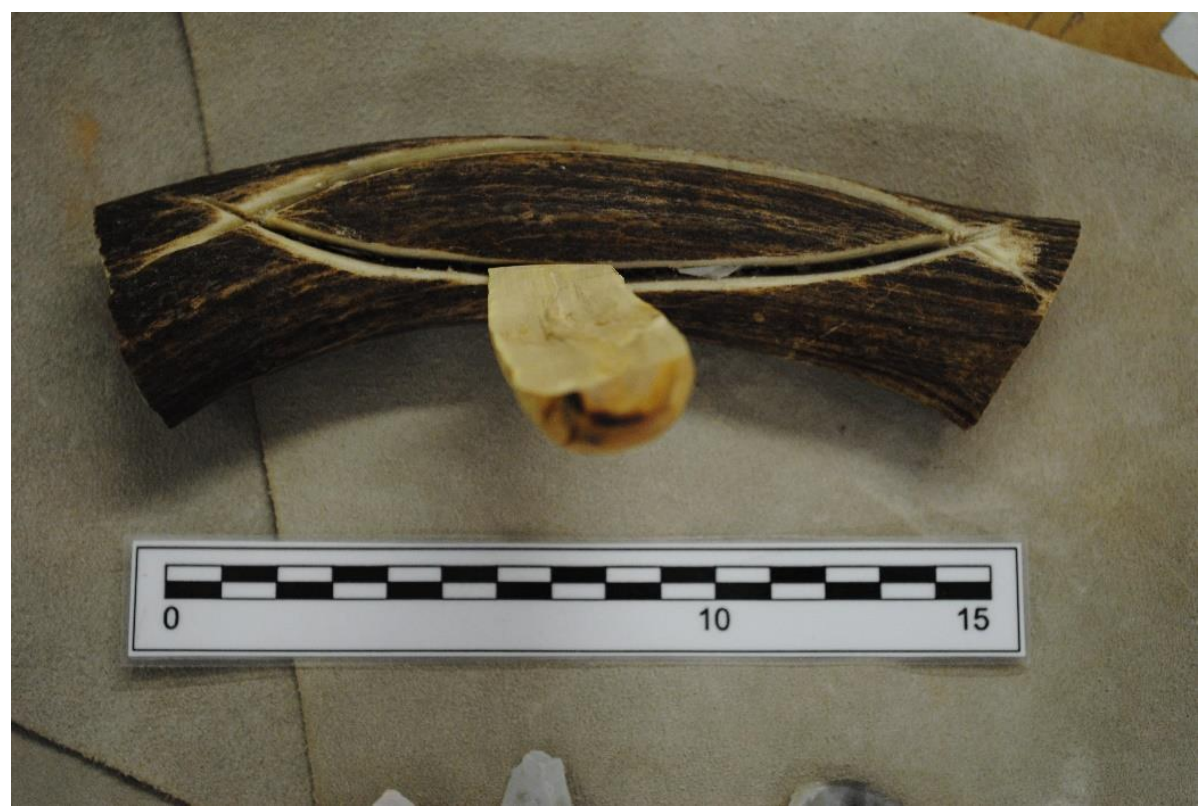

Figura 9. Taco de boj encajado en el surco durante la extracción. A su derecha podemos observar un resto de lasca de sílex que nos impedía apalancar en esa zona. 
B. Ugarte

Elaboración de un arpón magdaleniense: huellas de fabricación y uso a través de la arqueología experimental

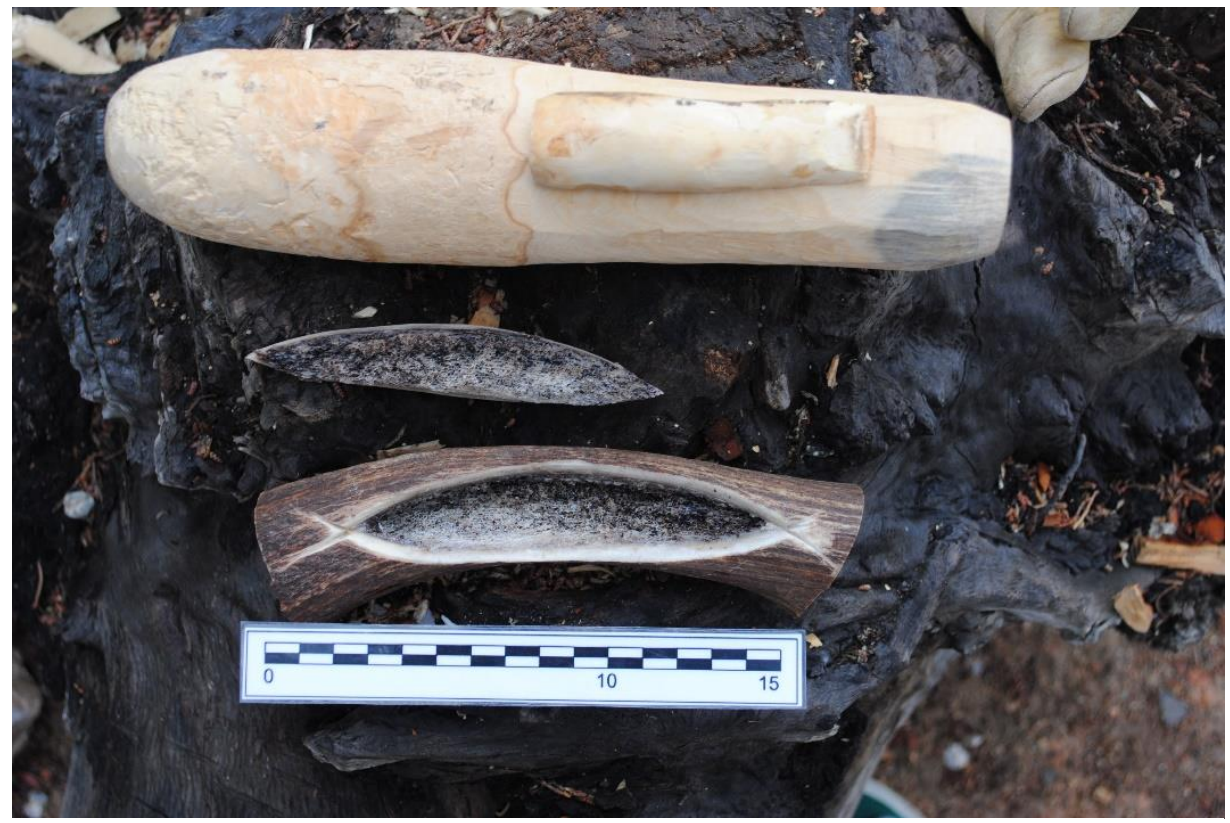

Figura 10. Matriz extraída del asta. Arriba percutor y taco de boj empleados para ello.

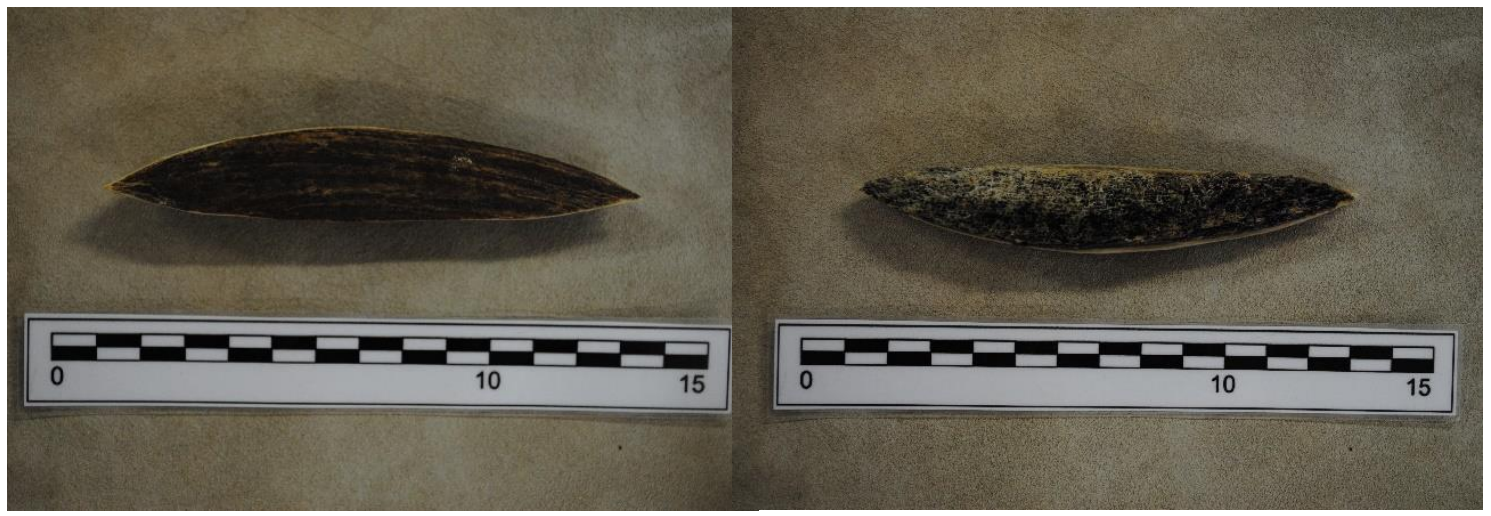

Figura 11. Matriz del arpón una vez extraída. Izquierda: cara cortical. Derecha: cara esponjosa.

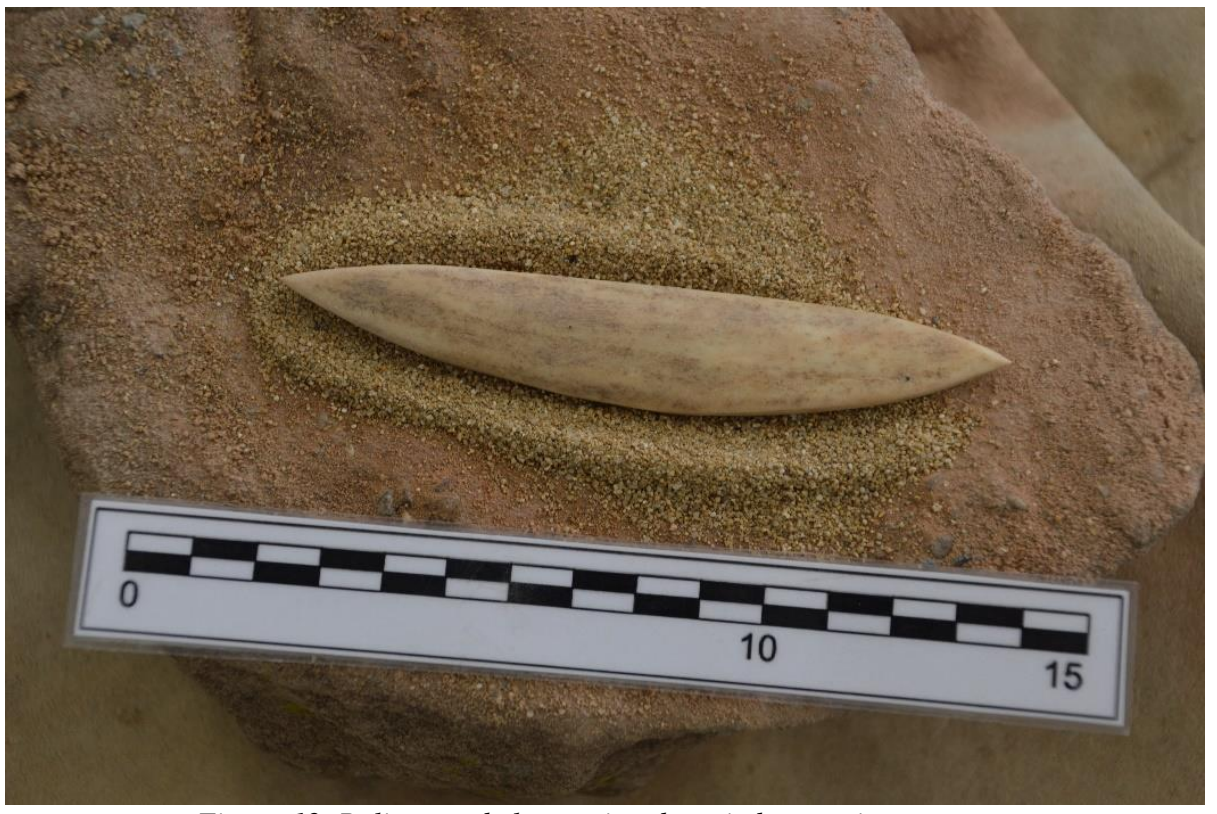

Figura 12. Pulimento de la matriz sobre piedra arenisca y arena. 
Una vez que la matriz estaba completamente pulida, me dispuse a recortar los dientes (Fig. 13) -dibujados con lápiz previamente de acuerdo al boceto para servirme de guíaaunque debido al tiempo disponible para finalizar el trabajo, tuve que acelerar el proceso empleando una segueta. Debido a esto, las marcas generadas en la parte interior de los dientes no nos sirvieron ya que fueron hechas con metal. El proceso de recortar los dientes duró 30 minutos.

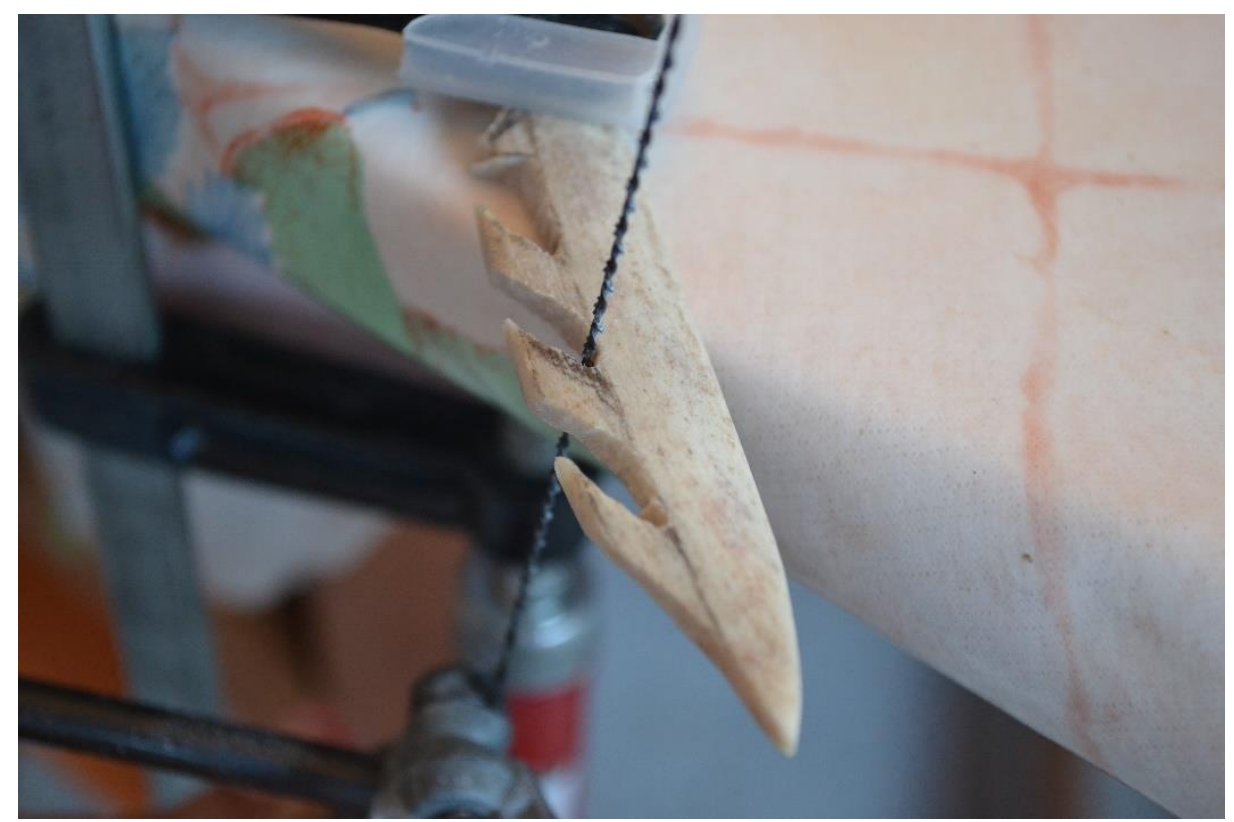

Figura 13. Recorte de los dientes con segueta para acelerar el proceso.

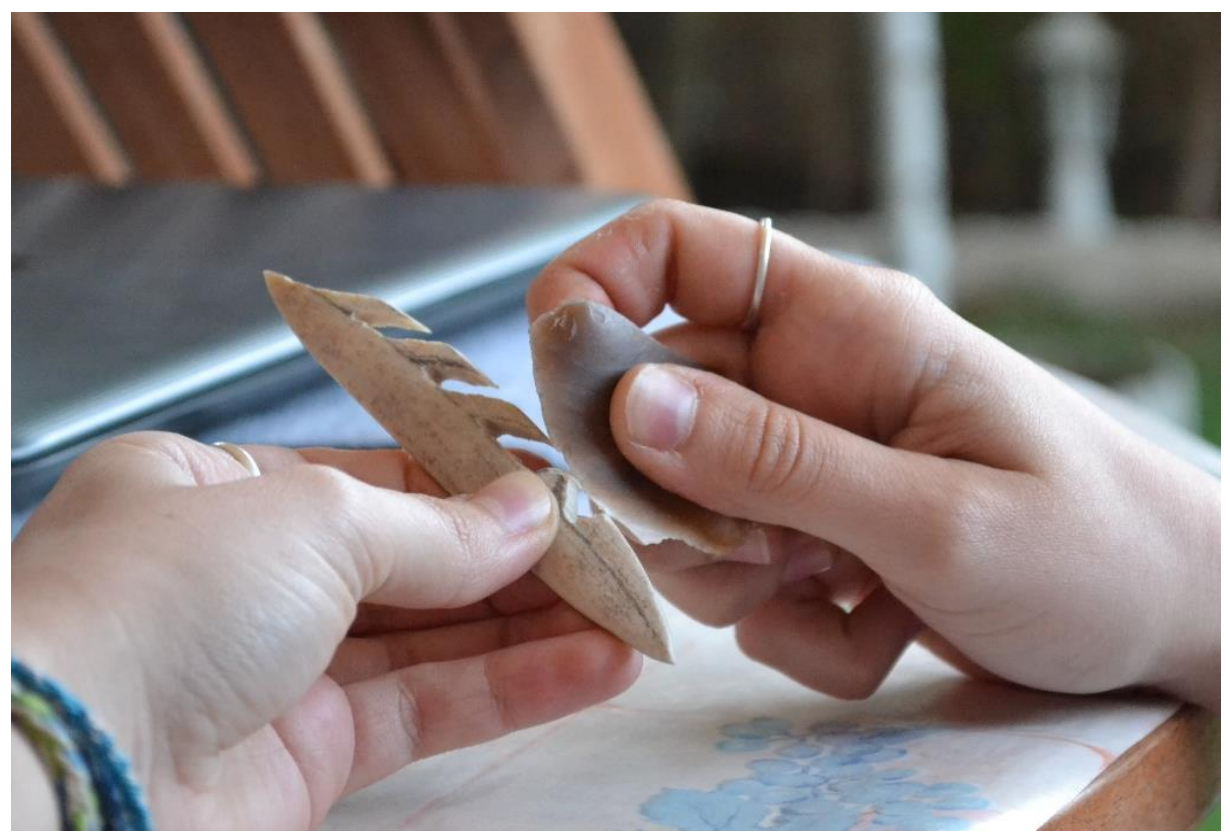

Figura 14. Recorte del abultamiento basal del arpón con una lasca de sílex.

Al igual que los dientes -en este caso, opté por realizar un arpón de una sola hilera de tres dientes- se añadían otros accesorios con diferente funcionalidad práctica como los abultamientos basales como tope a la hora de introducir el arpón en el vástago de madera (Barandiarán, 1967). Este autor propone que tanto los dientes como los abultamientos basales fueron definidos y delimitados en el periodo Magdaleniense con un buril de sílex, 

experimental

por lo que para el abultamiento basal derecho que había elegido hacer, utilicé buriles y lascas de sílex (Fig. 14), y así podría observar más tarde las marcas generadas.

A continuación, volví a pulir tanto el extremo distal como el proximal con el objetivo de conseguir una sección circular puesto que la eliminación completa del tejido esponjoso había provocado que la sección fuese cuadrangular y aplanada. Con ambos extremos pulidos hasta alcanzar una morfología más circular (Fig. 15), comencé con el enmangado al vástago de madera con tripa animal y cuerda de tendón de ciervo.

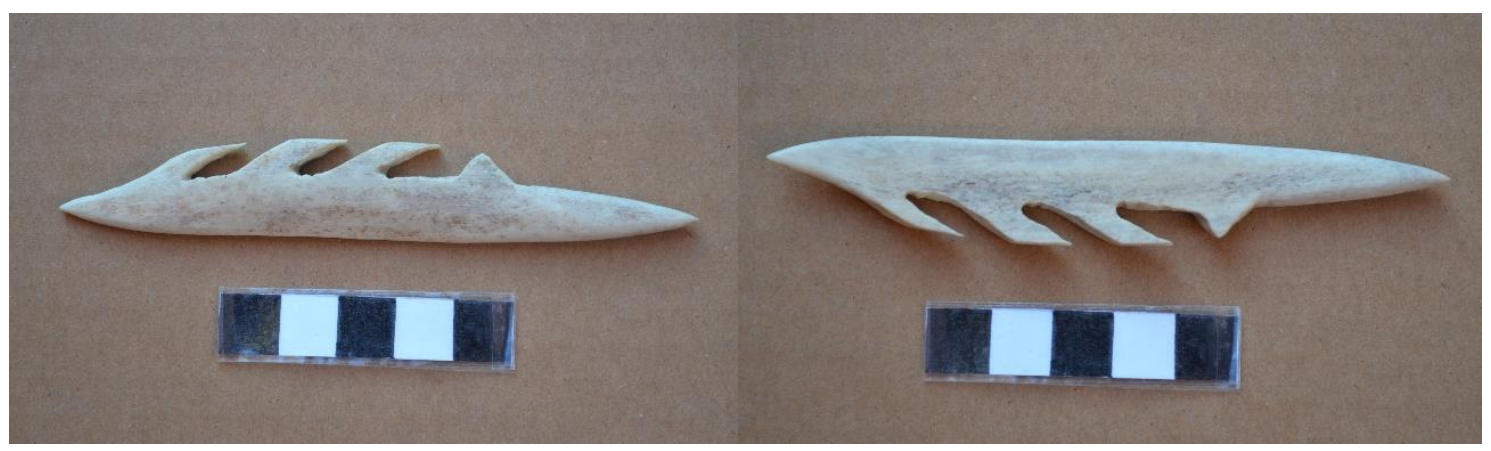

Figura 15. Arpón finalizado.

Previamente al enmangado realicé las observaciones oportunas al microscopio (Motic) que comentaré en el siguiente apartado- para no perder las marcas de la elaboración por solapamiento de las del enmangado y uso.

Para el enmangado utilicé un vástago de madera de pino de $2 \mathrm{~m}$ de longitud y un grosor de $2 \mathrm{~cm}$, ya que el arpón posee unas medidas finales de 11,5 cm de longitud, 1,5 cm de ancho (incluyendo los dientes) y 0,8 cm de grosor. En uno de los extremos de la varilla de madera realicé una hendidura con la segueta en la que encajar el extremo proximal del arpón hasta el abultamiento basal (Fig. 16). Una vez que la tripa se había descongelado y había estado en remojo unos 3 minutos comencé a estirarla para proceder al enmangado (Figs. 17 y 18). Una vez que lo completé, anudé dos cuerdas hechas con fibras de tendón de ciervo previamente extraídas para asegurar el enmangado.

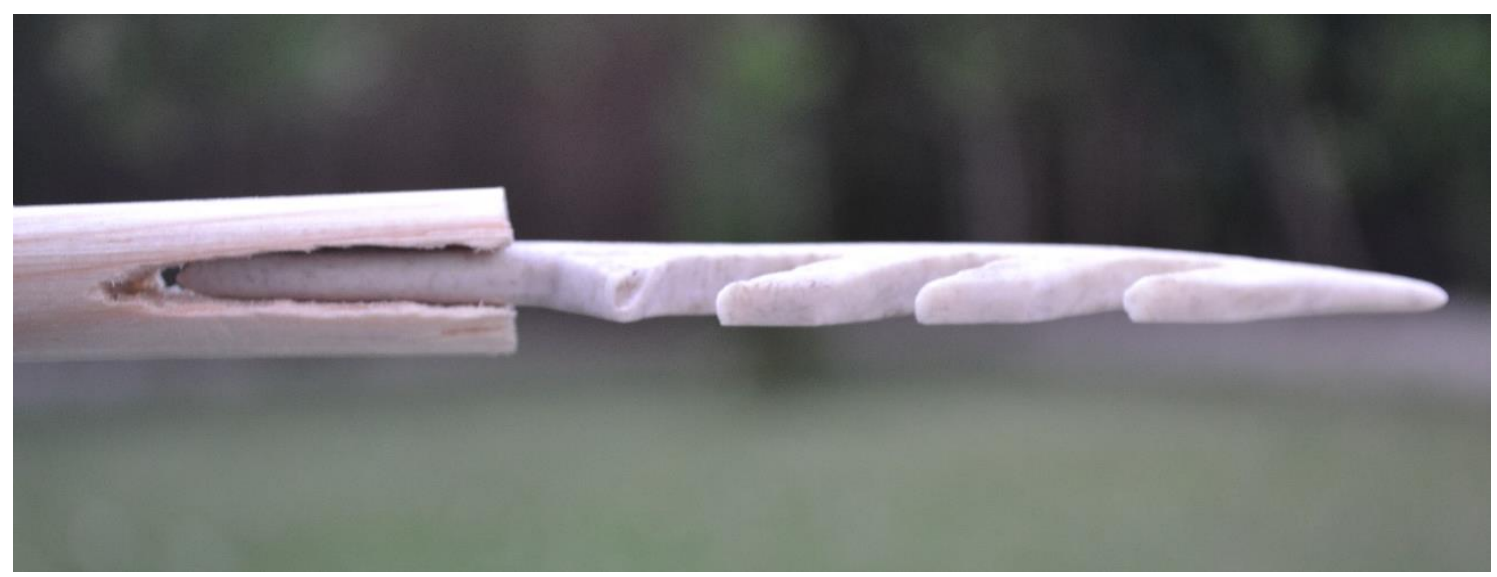

Figura 16. Inserción del arpón en el vástago de madera. 


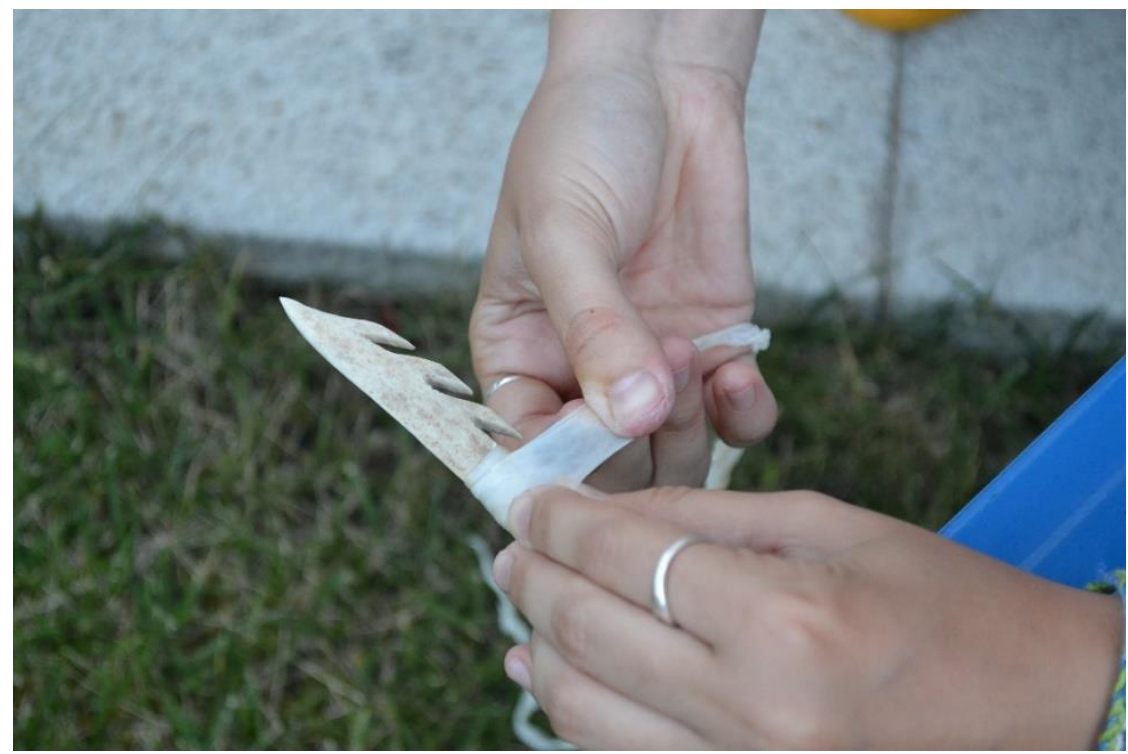

Figura 17. Enmangado con tripa animal.

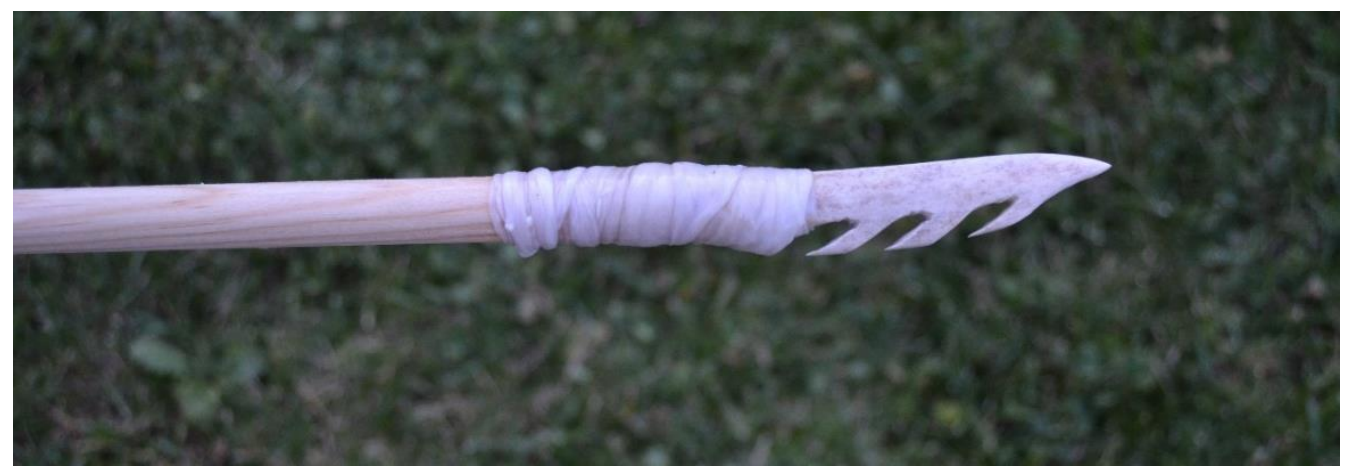

Figura 18. Enmangue del arpón.

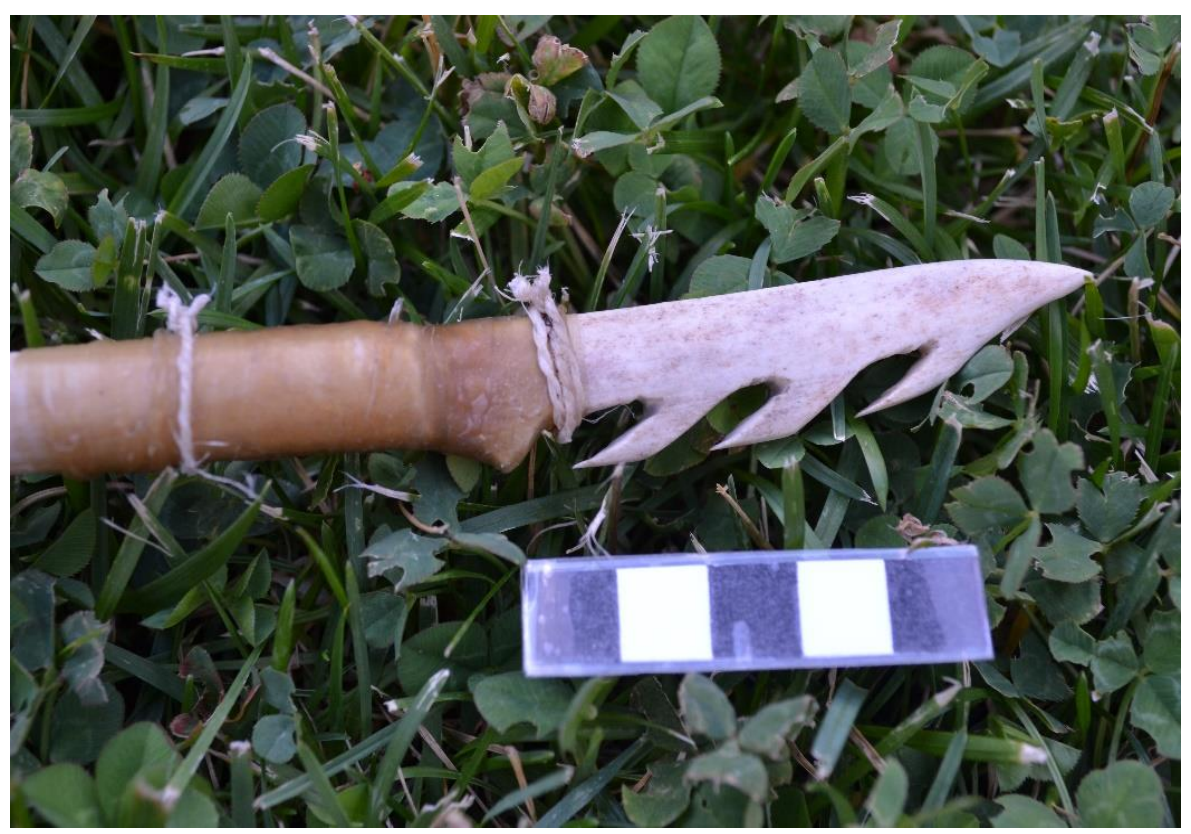

Figura 19. Enmangue después de 27 horas.

Después de 27 horas la tripa estaba seca (Fig. 19), adquirió una gran dureza y resistencia y comencé con la experiencia. 

experimental

\section{RESULTADOS TRACEOLÓGICOS COMPARADOS Y CONCLUSIONES}

Previamente al proceso de enmangado y experiencia del arpón -como ya he dicho-, recogí una serie de fotografías al microscopio en las que se pueden observar estrías de la utilización de lascas de sílex, así como marcas de pulimento en el arpón (Figs. 20, 21 y 22). Estas huellas si no son muy marcadas podrían llegar a borrarse como consecuencia del uso del arpón. Podemos comparar nuestros resultados con los del trabajo de Fano, Clemente y Rivero (2013) (Figs. 23 y 26) a pesar de que nuestro arpón no posee una perforación por la que pasar una cuerda, ya que nuestro modelo es fijo.

González (1986) corrobora la hipótesis de la vinculación del incremento de buriles con el incremento de la industria ósea. Esto parece ser confirmado por el análisis de las huellas de uso, donde efectivamente podemos observar huellas del sílex y otros procesos.

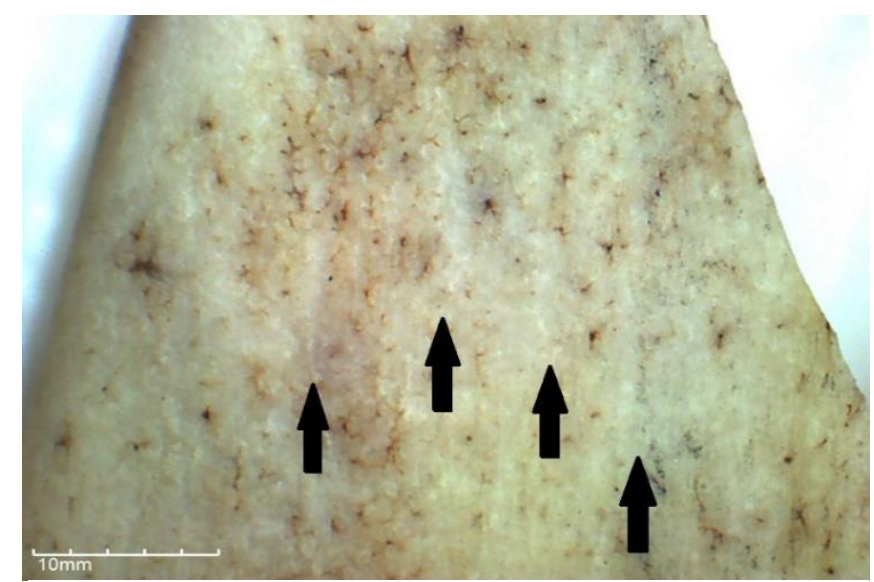

Figura 20. Marcas longitudinales resultado del trabajo con sílex. Aumentos X4.

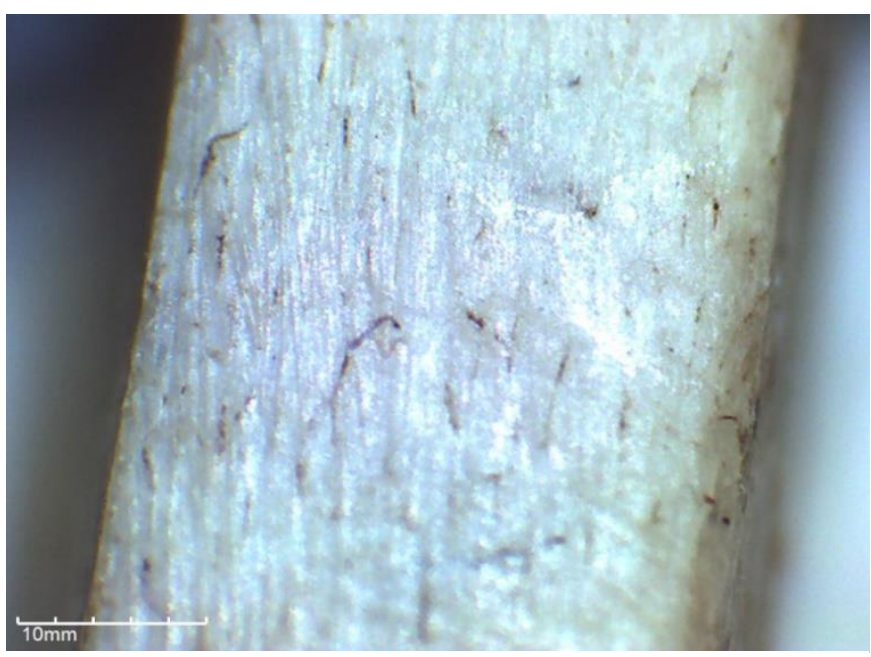

Figura 21. Marcas longitudinales y transversales resultado del trabajo con sílex. Aumentos $x 2$. 


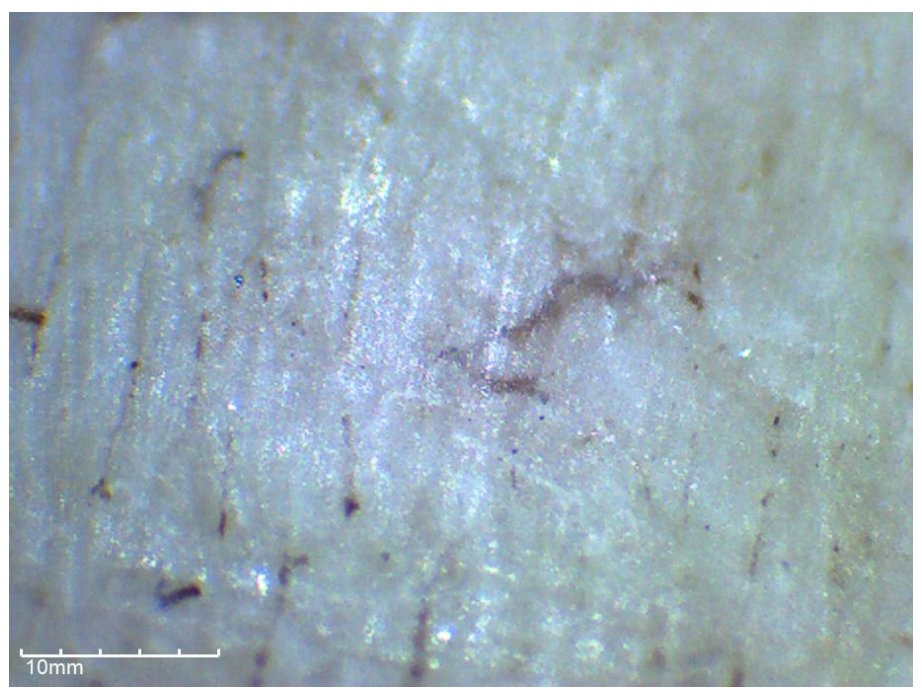

Figura 22. Brillo característico causado por el pulimento del asta. Aumentos $x 4$.

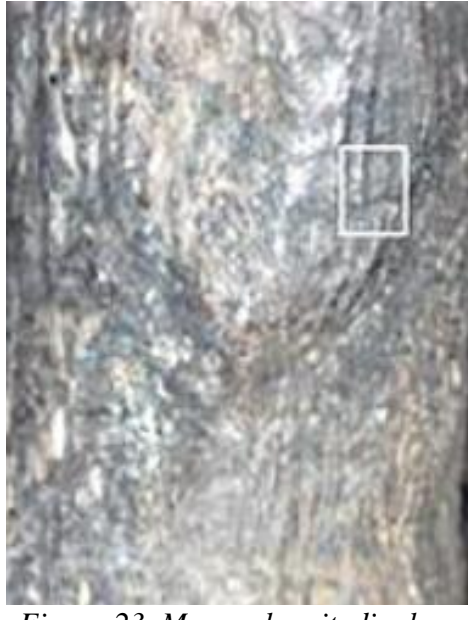

Figura 23. Marcas longitudinales más acusadas del trabajo sobre el arpón $n^{\circ} 2$ de El Horno (Fano, Clemente y Rivero, 2013).

Una vez dejada secar la tripa para asegurar su adherencia al arpón y al vástago, comencé la experimentación. En primer lugar, planteé la posibilidad de clavar repetidamente el arpón en la tierra (abonos, piedras, raíces) y lo realicé un total de 55 veces (Fig. 24). El problema de esta experimentación -y de cualquier otra para conseguir marcas del enmangado en el asta- es que la propia tripa cubre la zona del arpón que tenemos que observar por lo que durante la experiencia no nos es posible saber si está dando resultado o no. Debido a la escasa fuerza que se realiza al clavar el arpón en la tierra, decidí realizar mayor fuerza levantando un peso de $2 \mathrm{~kg}$. En este caso me serví de una botella de 21 . llena de agua que, atada con una cuerda al arpón, levanté y solté sin dejar caer al suelo sujetando el vástago, de manera que podía simular así el peso de un pez atrapado por el arpón (Fig. 25). Tras repetir esta experiencia 125 veces, creí haber levantado el peso adecuado como para que la tripa dejase alguna huella. Sin embargo, al retirar la tripa y las cuerdas y recuperar el arpón, a simple vista no observé ningún cambio excepto de coloración. Esto indicaría que la propuesta para dejar huellas no fue la apropiada o que el material utilizado para el enmangue en arpones arqueológicos no era tripa, sino cuerda de alguna materia vegetal u animal como el tendón de ciervo. Esto podemos observarlo claramente en la figura 26 del arpón no 3 de El Horno donde las marcas de cordaje en la perforación son más parecidas a las que dejaría una cuerda que una tripa. En nuestras imágenes de la observación al microscopio para el enmangado solo hemos observado un cambio de coloración (Fig. 27), ningún tipo de fricción ni pulimento, ni tampoco residuos. Esto confirma lo anterior y es que la experimentación con este tipo de enmangue no dio resultados. 
B. Ugarte

Elaboración de un arpón magdaleniense: huellas de fabricación y uso a través de la arqueología experimental

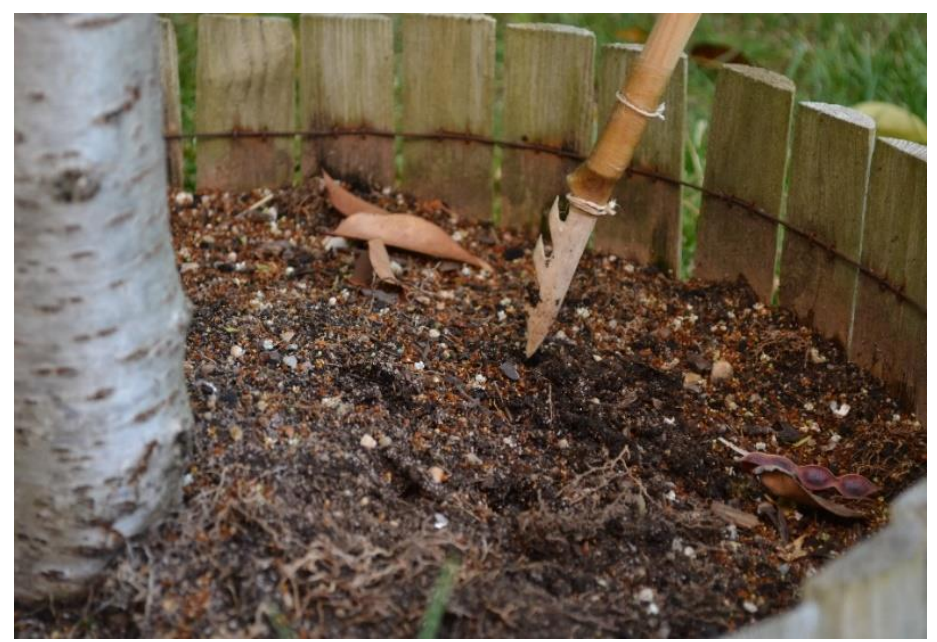

Figura 24. Experimentación para huellas de uso clavando el arpón sobre tierra.

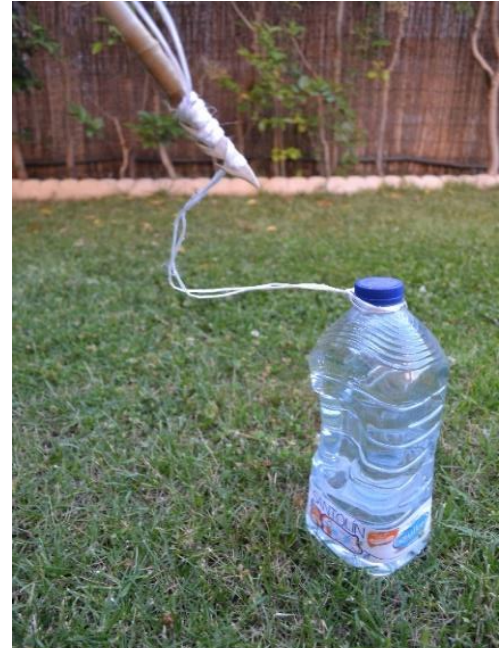

Figura 25. Otro tipo de

experimentación con peso.

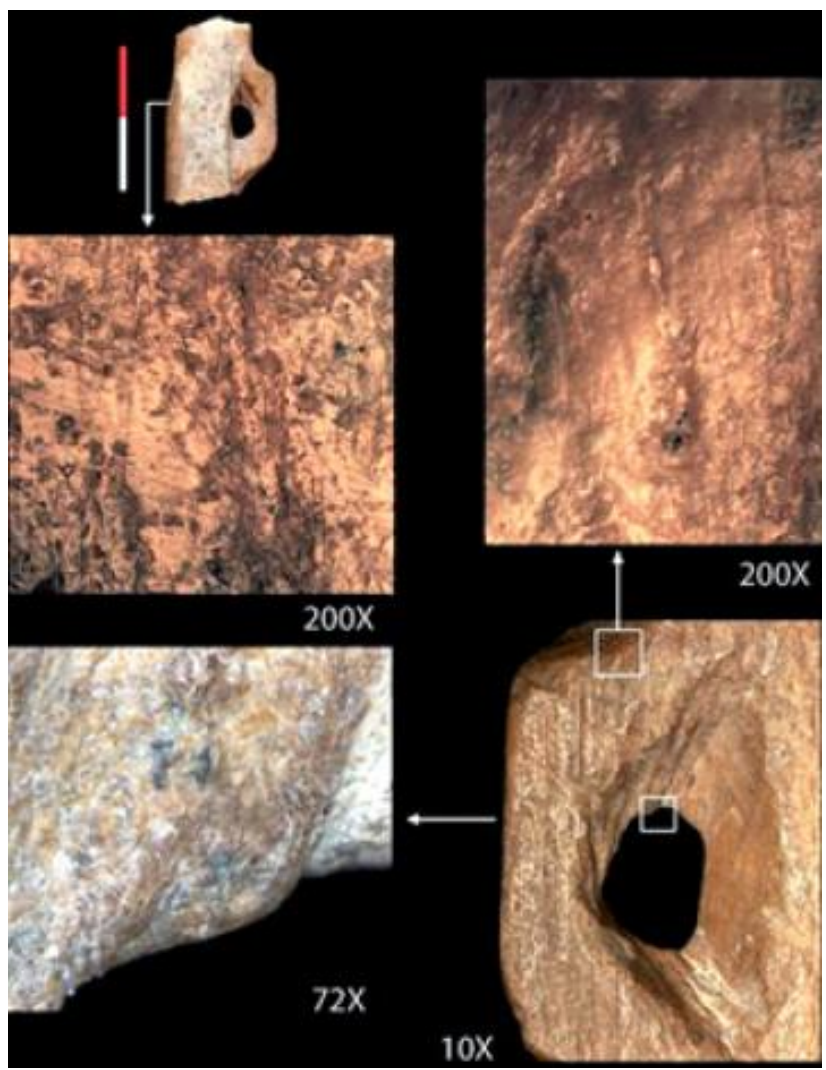

Figura 26. Marcas de la fricción de una cuerda en la perforación del arpón $n^{\circ} 3$ de El Horno, así como otras marcas de cordaje (Fano, Clemente y Rivero, 2013).

Sí que hemos hallado algunas huellas longitudinales debido al proceso de clavar el arpón en el suelo (Fig. 28), pero no hay rastro de marcas bajo el enmangado.

Hemos de destacar que la morfología del arpón influye en las marcas que quedarían por el uso ya que, al ser un arpón de sección cuadrangular en la zona mesial las huellas no serían iguales en todos los lados, sino que en algunos serían más definidas y en otros menos. Esto no ocurre con arpones de sección circular en los que por ejemplo la fricción de una cuerda atada genera marcas idénticas en todo su contorno. 
Además, es importante tener en cuenta la diferencia entre trabajar sobre asta fresca o sobre asta seca. En nuestro caso fue sobre asta seca por lo que el trabajo se ralentizó mucho.

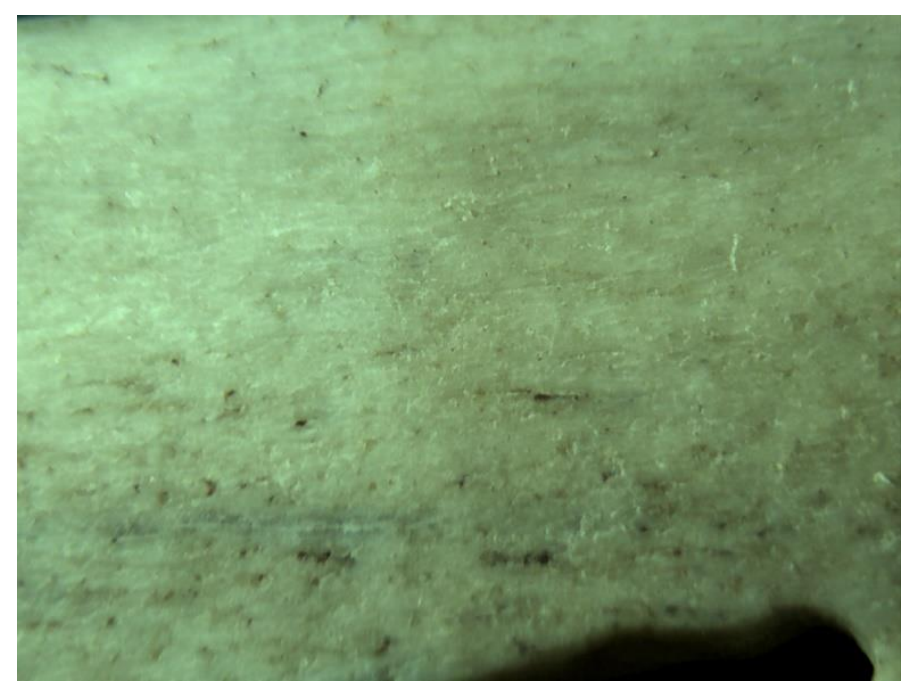

Figura 27. Cambio de coloración que se aprecia en torno a la mitad de la imagen. La parte derecha era la que estaba sin enmangar y la izquierda la enmangada.

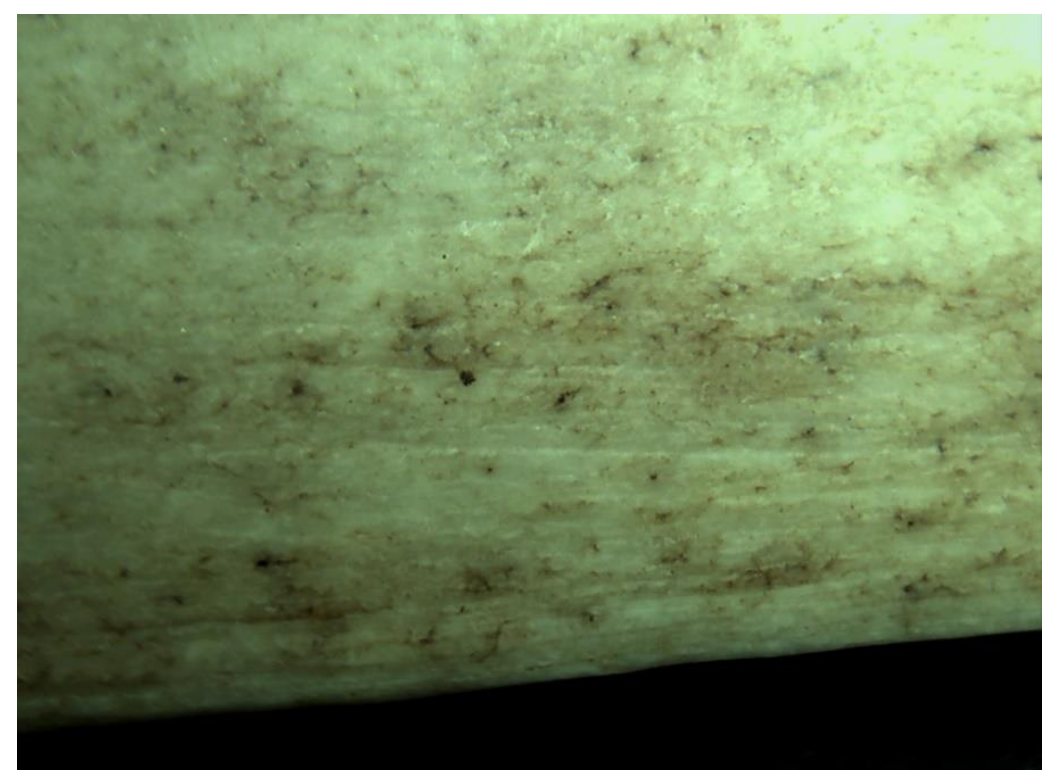

Figura 28. Marcas longitudinales generadas por la acción de clavar el arpón en la tierra. Estas marcas producen un solapamiento a las marcas de fabricación que se borran y no quedan como evidencias en arpones arqueológicos en el caso de que fuesen utilizados.

\section{Bibliografía}

BAENA, J. (1997): “Arqueología experimental, algo más que un juego". BAEX: Boletín de Arqueología Experimental, 1: 2-5. 
B. Ugarte

Elaboración de un arpón magdaleniense: huellas de fabricación y uso a través de la arqueología experimental

BARANDIARÁN, I. (1967): El Paleomesolítico del Pirineo Occidental. Bases para una sistematización tipológica del instrumental óseo paleolítico. Monografías arqueológicas, III, Universidad de Zaragoza, Zaragoza.

CARVALLO, J. (1960): Investigaciones prehistóricas. Vol. II, Museo Provincial de Prehistoria, Santander.

DIARIO DE LOS YACIMIENTOS DE LA SIERRA DE ATAPUERCA [Online]: "Perfeccionando la pesca. Elaborando nuestro arpón". Arqueología experimental, 20. http://www.diariodeatapuerca.net/UnArpon.pdf [Última consulta 18-3-2017].

FANO, M. A., CLEMENTE, I. y RIVERO, O. (2013): “Apuntes en torno al uso de los arpones magdalenienses: primeras observaciones microscópicas a partir de los materiales de El Horno (Ramales de la Victoria, Cantabria)". Trabajos de Prehistoria, 70 (2): 332345 .

GARCÍA-GELABERT, M. P. (2005): "El trabajo sobre hueso en el Magdaleniense Superior Final del grupo humano de la Cueva del Valle, Rasines, Cantabria. Campañas de los años 1996, 1997, 1998”. Zephyrus, 58: 111-134.

GONZÁLEZ, C. (1986): El Magdaleniense superior-final de la región cantábrica. Tesis doctoral. Universidad de Cantabria. Santander.

GONZÁLEZ, C. (1989): El Magdaleniense Superior-Final en la región cantábrica, Ed. Tantín, Santander.

GUTIÉRREZ, C. “Arqueología Experimental”. Universidad Autónoma de Madrid. 9-22017

JULIEN, M. (1982): Les harpons magdaléniens. Supplement à Gallia Préhistoire, XVII. Editions du CNRS, París.

MOURE, J. A. y ORTEGA, M. L. (1981): “Arpones inéditos del Magdaleniense de Cueva Morín (Santander)". Boletín del Seminario de Estudios de Arte y Arqueología, 47: 187199.

MUSEO ARQUEOLÓGICO DE ASTURIAS [Online]: "Fabricación de un arpón aziliense". Exposición permanente Los tiempos Prehistóricos (vídeos). https://www.museoarqueologicodeasturias.com/educaci\%C3\%B3n/videos [Última consulta 18-3-2017].

POKINES, J. T. y KRUPA, M. (1997): "Self-barbed antler spearpoints and evidence of fishing in the Late Upper Paleolithic of Cantabrian Spain". En H. Knecht (ed.): Projectile Technology. Plenum Press. New York y London: 241-262.

VILLALVERDE, V. y ROMÁN, D. (2005): "Los arpones del Magdaleniense superior de la Cova de les Cendres y su valoración en el contexto del Magdaleniense mediterráneo". Munibe. Antropologia y Arkeología, 57: 207-225. 


\title{
LOS MÉTODOS DE ILUMINACIÓN DURANTE EL PALEOLITICO EN LA PENÍNSULA IBÉRICA ${ }^{29}$
}

\author{
The Illumination Methods during the Paleolithic period in the \\ Iberian Peninsula
}

Lucía Esperanza Doral Chapado¡Error! Marcador no definido. ${ }^{30}$

\section{Resumen}

El descubrimiento del fuego por los hombres prehistóricos supuso un cambio sustancial en la vida de estos hombres, de sus costumbres y usos diarios como la defensa contra los animales salvajes, los cambios producidos en su alimentación, e incluso una forma de combatir el frio. Además, fue un elemento indispensable para poder combatir la oscuridad dentro de las cuevas y grutas donde se refugiaron. A pesar de ello, no son muchos los historiadores que han profundizado en el estudio de la iluminación y su relación con el arte rupestre; cabe mencionar entre otros a María Ángeles Medina; Araceli Cristo; Antonio Romero, José Luis Sanchidrián o Sophie A. de Beaune.

La aparición de las lámparas hace 40.000 años posiblemente favoreció la aparición del "arte" en cuevas y grutas, pinturas, adornos personales, armas más complejas, etc. Por eso es imprescindible conocer qué tipo de combustible y de mecha era el más idóneo para la fabricación de estas lámparas.

En el presente trabajo se ha estudiado la eficacia (duración e iluminación) de tres tipos de combustibles disponibles en aquella época: cera de abeja, sebo y tuétano, con la misma mecha y el mismo soporte-

Nuestros resultados indican que el combustible más idóneo en las condiciones del experimento sería el tuétano.

Palabras clave: Paleolítico Superior, lámparas, combustible, mecha.

\begin{abstract}
The discovery of fire brought with it a considerable change in the lives of those men across several aspects in their customs and daily uses such as defense against wild animal, changes in their diet and even way to fight the cold. Nevertheless, without doubt, it was an essential element to combat the darkness inside the caves and grottos where they took refuge. However, there are not many historians who have given importance to the study of lighting and its relationship with cave painting. But, it is worth mentioning among others María Ángeles Medina, Araceli Cristo, Antonio Romero, José Luis Sanchidrián o Sophie A de Beaune.
\end{abstract}

The appearance of lamps 40.000 years ago was parallel to the appearance of art in caves and grottos, paintings, personal ornaments, weapons that are more complex, etc. That why it is essential to know what type of fuel and wick was the most suitable for manufacturing these lamps.

\footnotetext{
${ }^{29}$ Recibido: 22/12/2018. Aceptado: 10/01/2019. http://doi.org/10.15366/baexuam2018-19.13.007

30 Universidad Autónoma de Madrid. ORCID: 0000-0002-7047-2009. E-mail: lucia.doral@estudiante.uam.es
} 
In this work, we have studied the efficiency (length and illumination) of three kinds of fuel: bee wax, tallow and marrow, with the same wick and bracket.

Our results show that the ideal fuel in the conditions of the experiment is marrow.

Keywords: Upper Paleolithic, lamps, fuel, wick

\section{INTRODUCCIÓN}

Con este trabajo pretendemos dar un poco de luz a un hecho fundamental que ha pasado inadvertido para muchos historiadores, como fue el descubrimiento del fuego por los hombres prehistóricos. Este gran descubrimiento permitió a estos hombres un cambio sustancial en sus vidas, abarcando varias facetas en sus costumbres y usos diarios como la defensa contra los animales salvajes, los cambios producidos en su alimentación, e incluso una forma de combatir el frio. Pero sin duda fue un elemento indispensable para poder combatir la oscuridad dentro de las cuevas y grutas donde se refugiaron. A pesar de ello, no son muchos los historiadores que han profundizado en el estudio de la iluminación y su relación con el arte rupestre; cabe mencionar entre otros a María Ángeles Medina; Araceli Cristo; Antonio Romero, José Luis Sanchidrián o Sophie A. de Beaune.

La aparición de las lámparas hace aproximadamente 40.000 años fue paralela a uno de los cambios culturales más importantes que se produjeron en la historia, la aparición del "arte", pinturas, adornos personales, armas más complejas, etc. Es plausible pensar que la utilización de las lámparas favoreció el desarrollo del arte murario en las cuevas y grutas, ya que éstas aportaban luz en las profundidades de estos lugares. Por eso es imprescindible conocer qué tipo de combustible y de mecha era el más idóneo para la fabricación de estas lámparas.

Hay indicios del uso del tuétano como combustible, ya en el Paleolítico Superior para realizar las pinturas, pero se han hallado restos en Atapuerca que pueden datar del Paleolítico Medio o Inferior (Diario de los yacimientos de Atapuerca). Además, este combustible se transforma en una especie de aceite que no emite humo, convirtiéndose en un elemento imprescindible para asegurar el resultado de estos artistas rupestres. Dichas lámparas entraron a formar parte de los útiles comunes en la vida de estos hombres y mujeres prehistóricos.

Los estudios realizados en la cueva malagueña de Ardales por Pedro Cantalejo y María del Mar Espejo desvelan el uso frecuente de cera de abeja como combustible, que aporta una luz más duradera y clara, que la de grasa de animal (Caso, 2011).

Siguiendo los estudios de Sophie A. Beaune (1987:109) podemos destacar otros tipos de combustible utilizados para hacer lámparas en la prehistoria, entre ellos; minerales (carbón, lignitos y petróleo); vegetales (árboles, arbustos, algas, turbas, raíces, resina y aceites de frutas).

Aunque es un misterio aún sin resolver lo que llevó a los hombres de la prehistoria a fabricar antorchas y lámparas con un hueso de un animal y una mecha, hoy sabemos por qué funcionó: la grasa del tuétano se funde con el calor y sube por la mecha por capilaridad. Parte de esa grasa que asciende se transforma en gas, y este arde en el extremo de la mecha, haciendo que la llama perdure durante un tiempo. Para determinar la mecha que se utilizaba, se han analizado los residuos de las lámparas y se han encontrado restos de coníferas, enebro, hierbas o liquen y musgo. 
Estos útiles nos han llegado en forma de materiales arqueológicos, que nos acercan a un conocimiento mayor, y nos ayudan a comprender mejor algunos de los aspectos más complejos de la espiritualidad e imaginario de este periodo. Este invento supuso un acicate en la búsqueda sobre todo de lugares adecuados para la realización de sus pinturas parietales. No podemos olvidar que la mayoría de los descubrimientos de los paneles más impresionantes se ubican en la profundidad de las cavidades, en galerías y espacios sumidos en la total oscuridad y donde sería necesaria por tanto la luz artificial.

Los estudios realizados a este respecto distinguen entre tres estilos de iluminación en cuevas: lámparas de piedra, antorchas y foyers. Las lámparas de grasa animal pueden a su vez ser de circuito abierto o cerrado (Fig. 1). Las primeras están constituidas por superficies planas o leves concavidades, que no recogen todo el combustible en el soporte, sino que lo dejan fluir fuera del recipiente. Por el contrario, las segundas pueden o no tener un mango, pero su característica principal es una especie de cazuela, bien natural o trabajada (de Beaune, 2000)
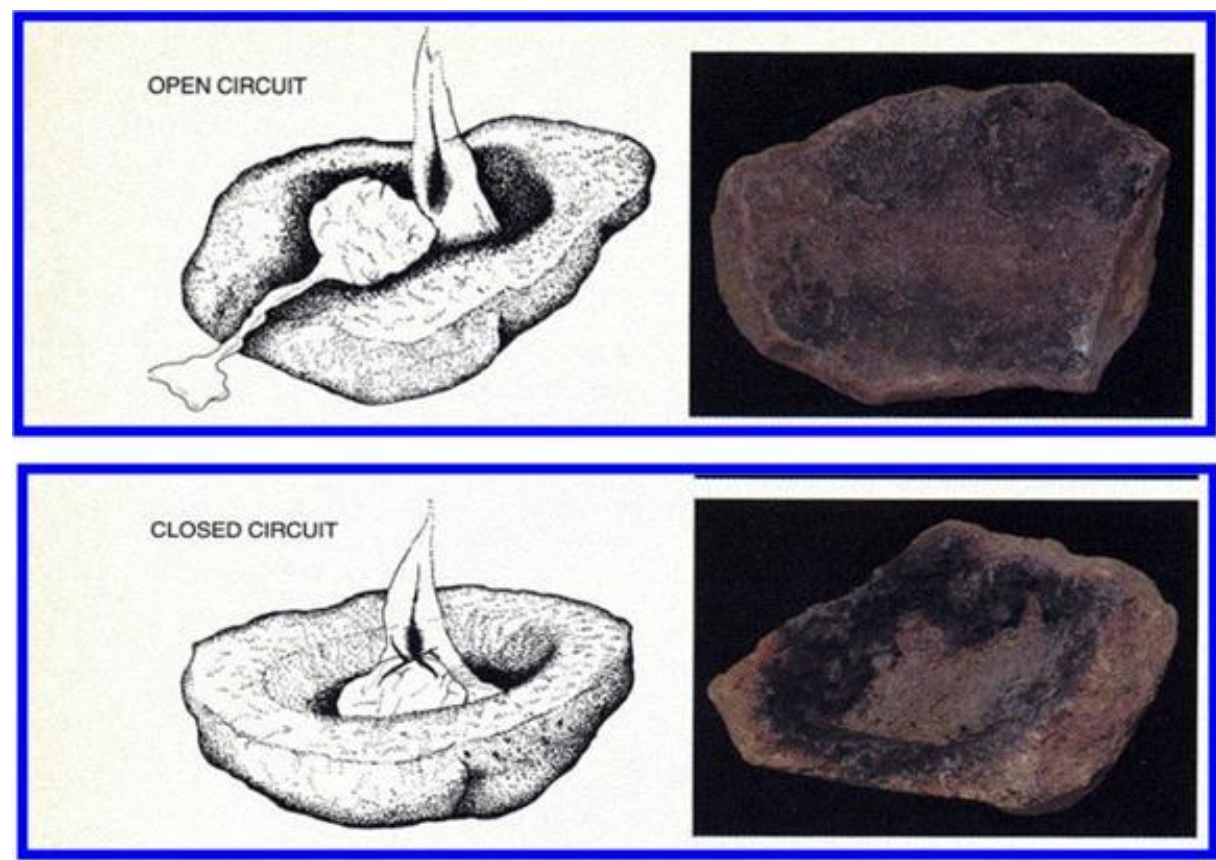

Figura 1. Lámparas de grasa animal.

Las que se han encontrado en la cueva de Llonin (Asturias) son de circuito cerrado sobre arenisca roja y son puntos de luz móviles (Fig. 2).

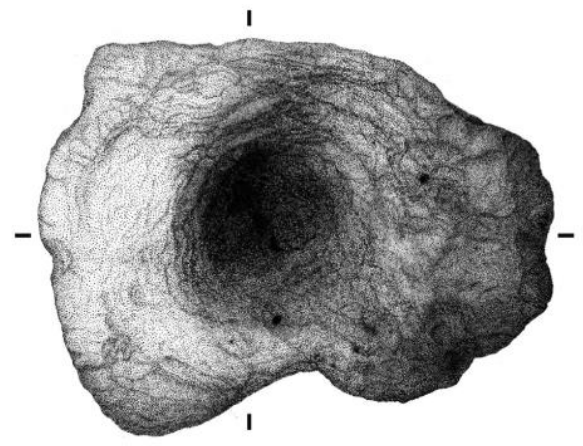

Figura 2. Lámpara de Llonin. Imagen obtenida de De la Rasilla et al., 2010. 
Con relacion a las antorchas, presentan la ventaja de dar más luz e iluminar en todas las direcciones y ademas iluminaban el suelo evitando que sufriesen accidentes al estar en lugares irregulares. Pero presentaban el incoveniente de durar menos tiempo y limitaba la movilidad del porteador.

"Los foyers son combustiones para iluminar y alimentar las lámparas y antorchas utilizadas durante el tránsito por la cavidad; se diferencian de los hogares en los restos que contiene en el interior, en su exclusiva utilización de alumbrado y, por lo general, se encuentran en lugares más profundos de la cavidad y sus restos se hallan más dispersos" (Medina et al., 2012:107).

El mayor número de lámparas se han encontrado en cuevas del norte peninsular: Llonin; El Pendo; Tito Bustillo; Covarón, etc. (de la Rasilla et al., 2010) coincidiendo con las zonas donde hay una mayor concentracion de cuevas con pinturas rupestres. En cuanto al sur de la península, se han hallado lámparas en cuevas malagueñas, como por ejemplo, en Cueva de Ardales (Cantalejo et al., 2014), la Cueva de la Pileta (Cortés et al., 2016) y en cuevas granadinas como la Cueva del Malmamuerzo.

El objetivo del experimento que se propone hacer dentro del campo de la Arqueología Experimental es fabricar, de forma artesanal e imitando la técnica del Paleolítico, una lámpara de piedra con una convexidad para albergar el combustible y determinar qué tipo es el que proporciona una mayor intensidad de luz y cuál permite un tiempo mayor de uso, a tenor de los estudios previos sobre este tema expuestos en el inicio del trabajo. Hay que tener en cuenta que el tamaño de la lámpara fabricada es de una capacidad menor, en comparación con las que nos encontramos en los yacimientos.

- Las variables fijas son el soporte, la cantidad de combustible y el tamaño de la mecha.

- Las variables independientes son: la grasa de tuétano de un hueso de animal, el sebo de un animal y la cera virgen de abeja.

- Las variables dependientes son la intensidad de la luz y su tiempo de duración.

- La observación se hará a través de un luxómetro HANNA modelo HI 97500 del Laboratorio de Prehistoria y Arqueología de la Universidad Autónoma de Madrid (Fig. 3), al igual que la báscula de precisión que se utilizó para pesar los distintos combustibles. 


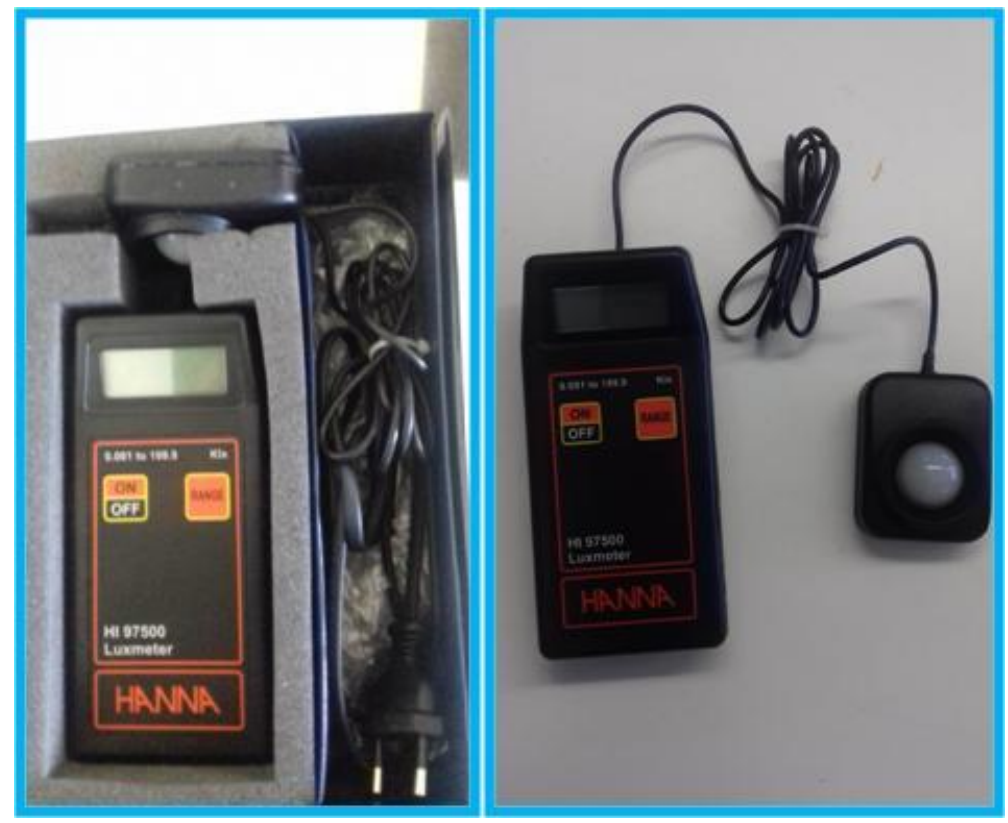

Figura 3. Luxómetros utilizados en el trabajo

\section{Experimento 1}

Cera de abeja y mecha de estopa.

\section{Experimento 2}

Tuétano y mecha de estopa

\section{Experimento 3}

Sebo de animal y mecha de estopa

\section{PROCEDIMIENTO}

Lo primero es proceder a la fabricación de la lámpara. Para ello se utiliza una piedra de arenisca del noroeste peninsular. Tras marcar con un lápiz el diámetro que necesitamos para depositar dentro el combustible, se pasa a hacer una concavidad mediante la técnica de repiqueteado y abrasión. Se utiliza un canto de cuarcita de río para esta última técnica y un percutor o pico de cuarcita procedente de afloramientos de Ciudad Real y otro de sílex del Mioceno de Madrid para la primera (Figs. 4 y 5). El tiempo de ejecución ha sido de 13 horas, en las cuales se han tenido que ir retocando las herramientas para sacar filo y facilitar el trabajo. 


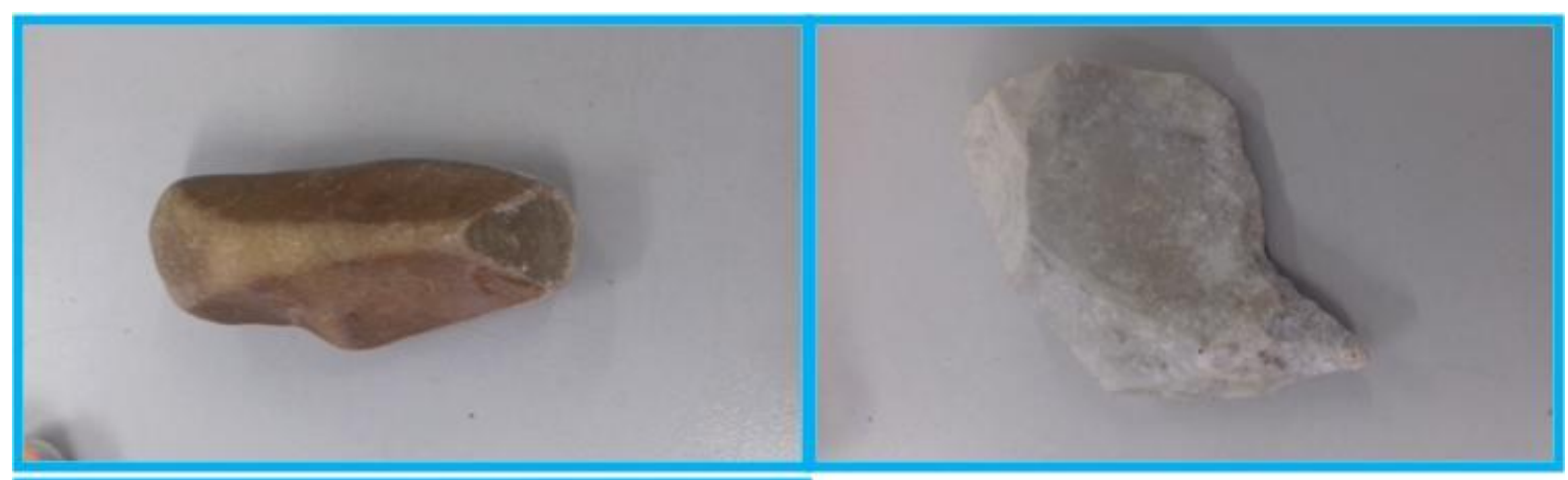

Figura 4. Herramientas empleadas
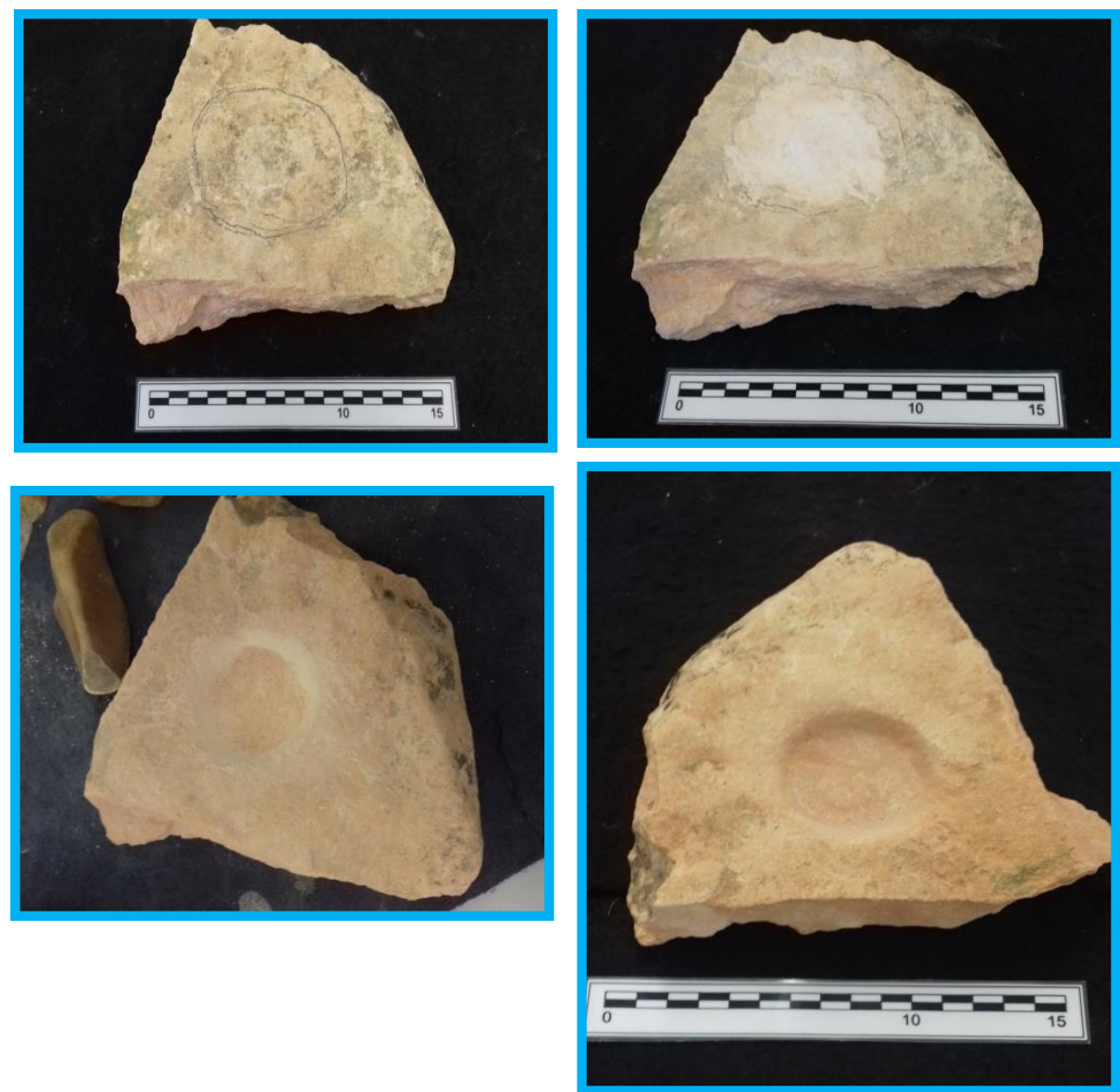

Figura 5. Secuencia de fabricación de la lámpara 
En segundo lugar, se han fabricado las tres mechas (Fig. 6). El material utilizado ha sido estopa, se han trenzado unos $6 \mathrm{~cm}$ de ella para cada mecha y se han engrasado con el tuétano.

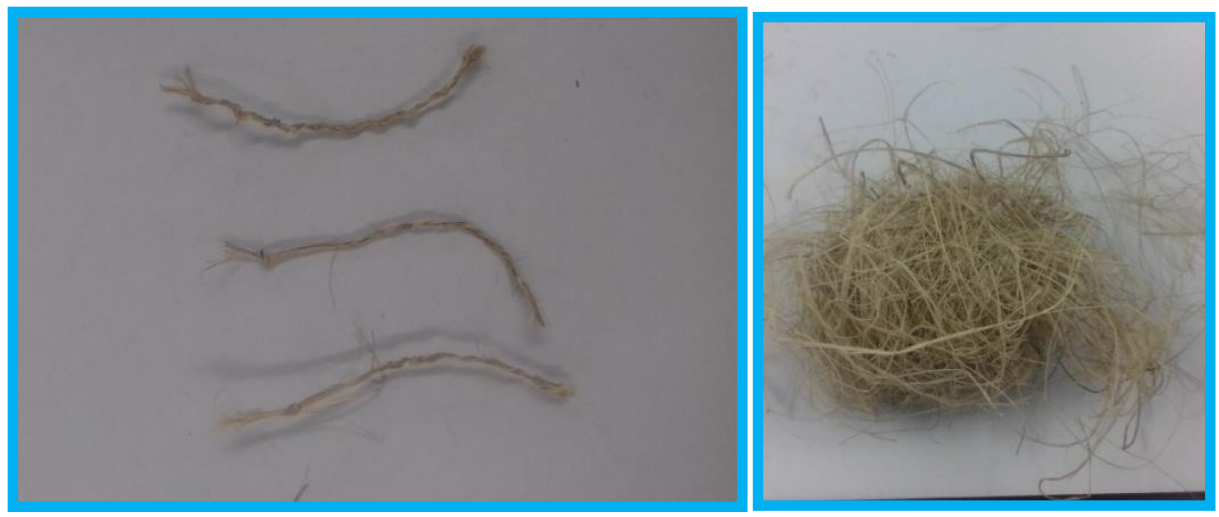

Figura 6. Mechas

En tercer lugar, procedimos a pesar $24 \mathrm{~g}$ de cada combustible (Fig. 7).

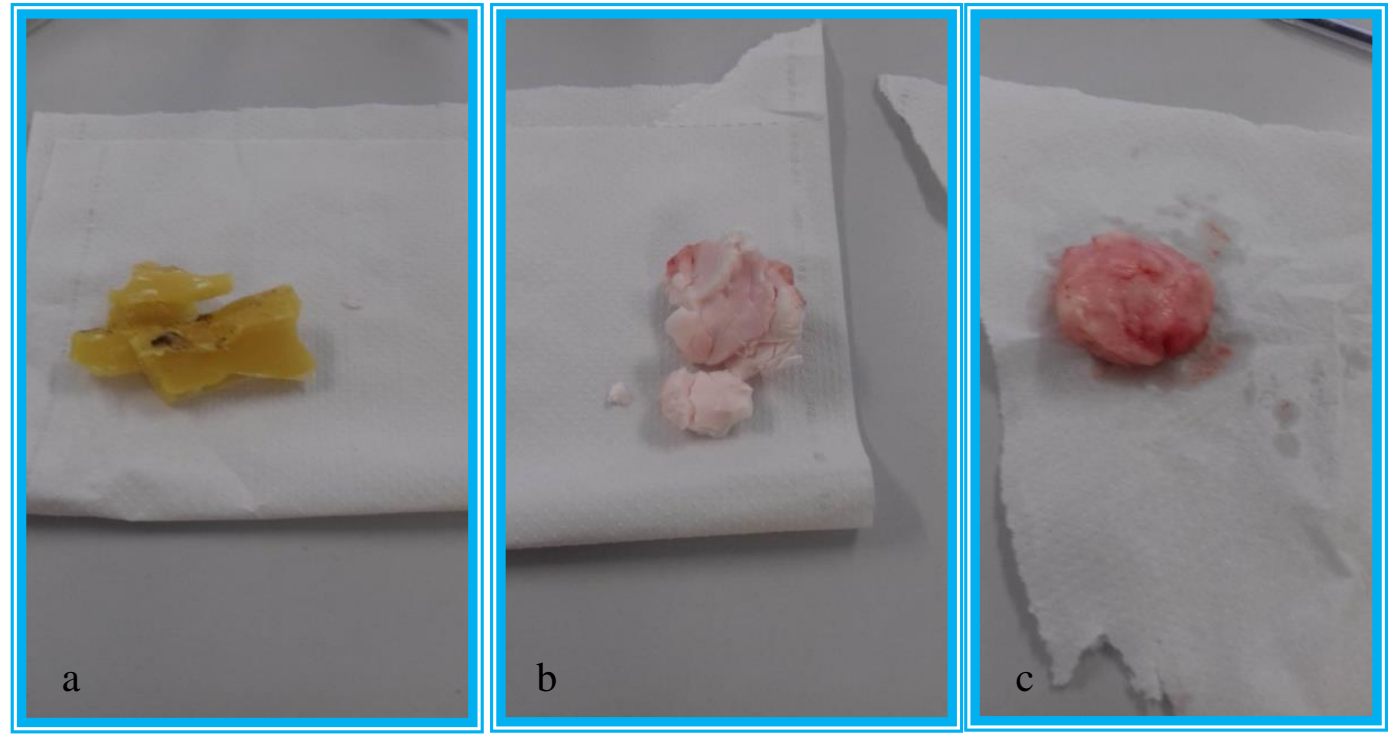

Figura 7: Combustibles: a) cera; b) tuétano; c) sebo

Por último, pasamos a ejecutar la preparación de cada combustible con su mecha. Para la lámpara de cera de abeja primero amasamos con las manos para calentar los $24 \mathrm{~g}$ de cera y ablandarla durante una hora, y después introducimos la mecha dejándola sobresalir unos dos centímetros. Para extraer el tuétano del hueso se ha utilizado un elemento afilado en la punta y, tras darle forma, se ha introducido la mecha dejando dos centímetros en la superficie. Para la lámpara de sebo ha sido necesario amasar también unos quince minutos antes de introducir la mecha.

\subsection{Primer experimento}

Con la lámpara de cera, en el momento de encender la mecha acercamos el luxómetro al borde de la lámpara y nos da 0,13 lx; volvemos a medir la intensidad lumínica a la media hora y nos da 0,03 lx; pasada una hora desde que se encendió la mecha, la llama es muy pequeña y apenas da luz, y se apaga pasadas dos horas y media desde su inicio, sin consumirse todo el combustible (Fig. 8). 


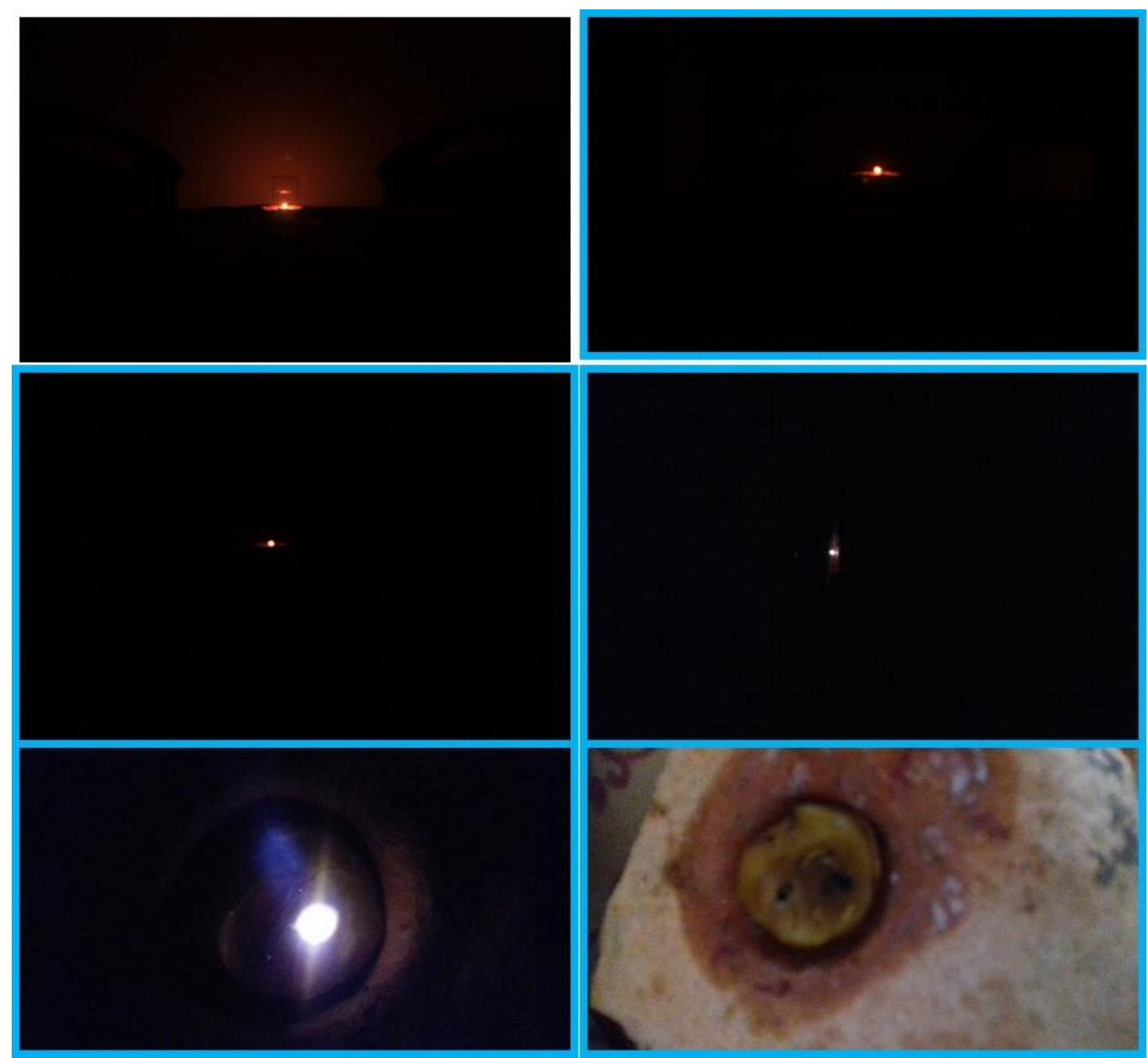

Figura 8. Lámpara de cera. Evolución de la iluminación

\subsection{Segundo experimento}

La lámpara de tuétano al inicio del experimento da 0,12 lx de intensidad lumínica. A la hora del inicio 0,02 lx. A las dos horas da 0,02 lx. A las tres horas 0,03/0,04 lx. A las cuatro horas da 0,10 lx. A las cuatro horas y media da 0,15 lx. A las cinco horas da 0,20/0,23 lx. A las cinco horas y media da 0,13 lx. A las seis horas da 0,10 lx. A las seis horas y diez minutos da 0,02 lx. Y a las seis horas y media se apaga (Figs. 9 y 10). 


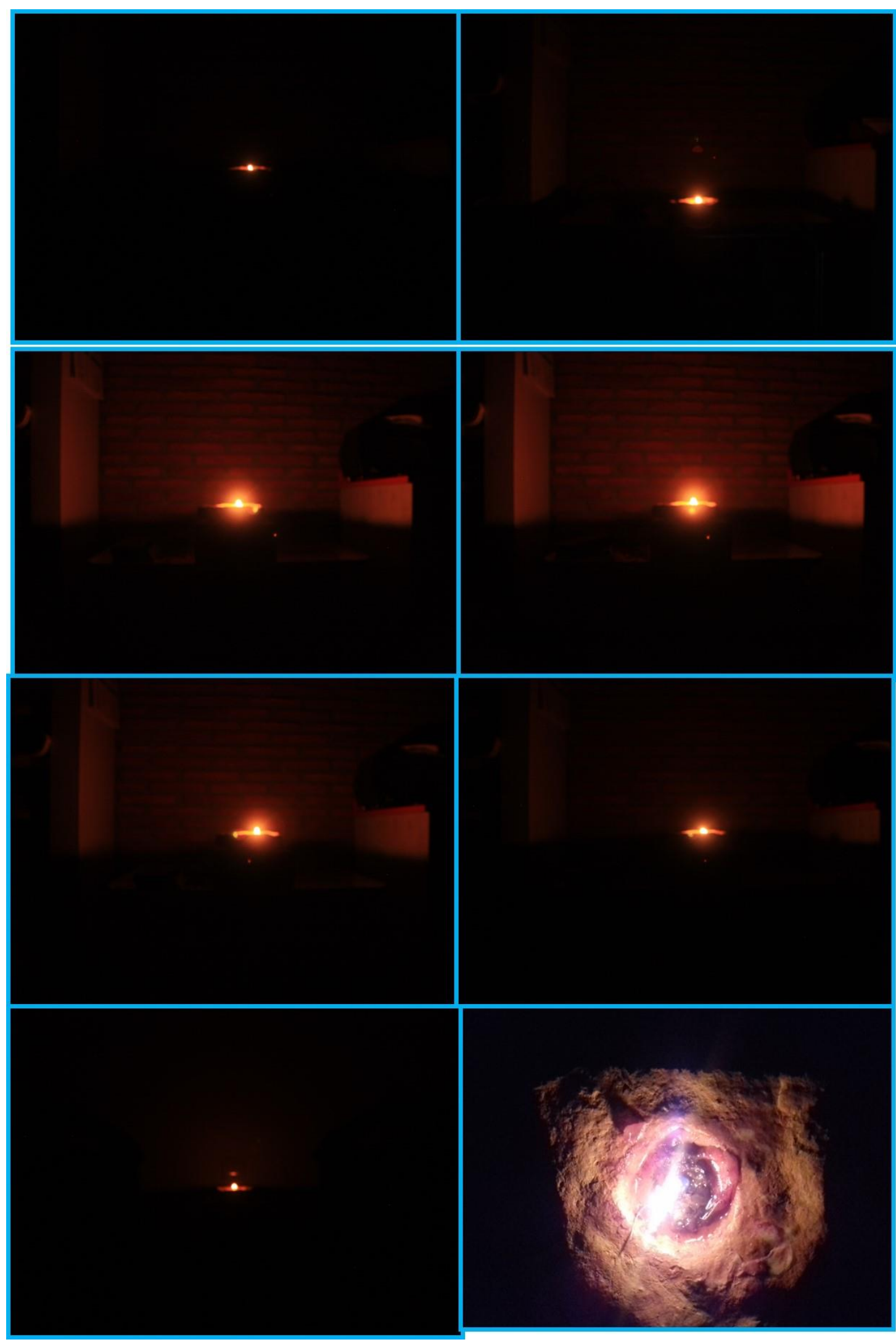

Figura 9: Lámpara de tuétano. Evolución de la iluminación 


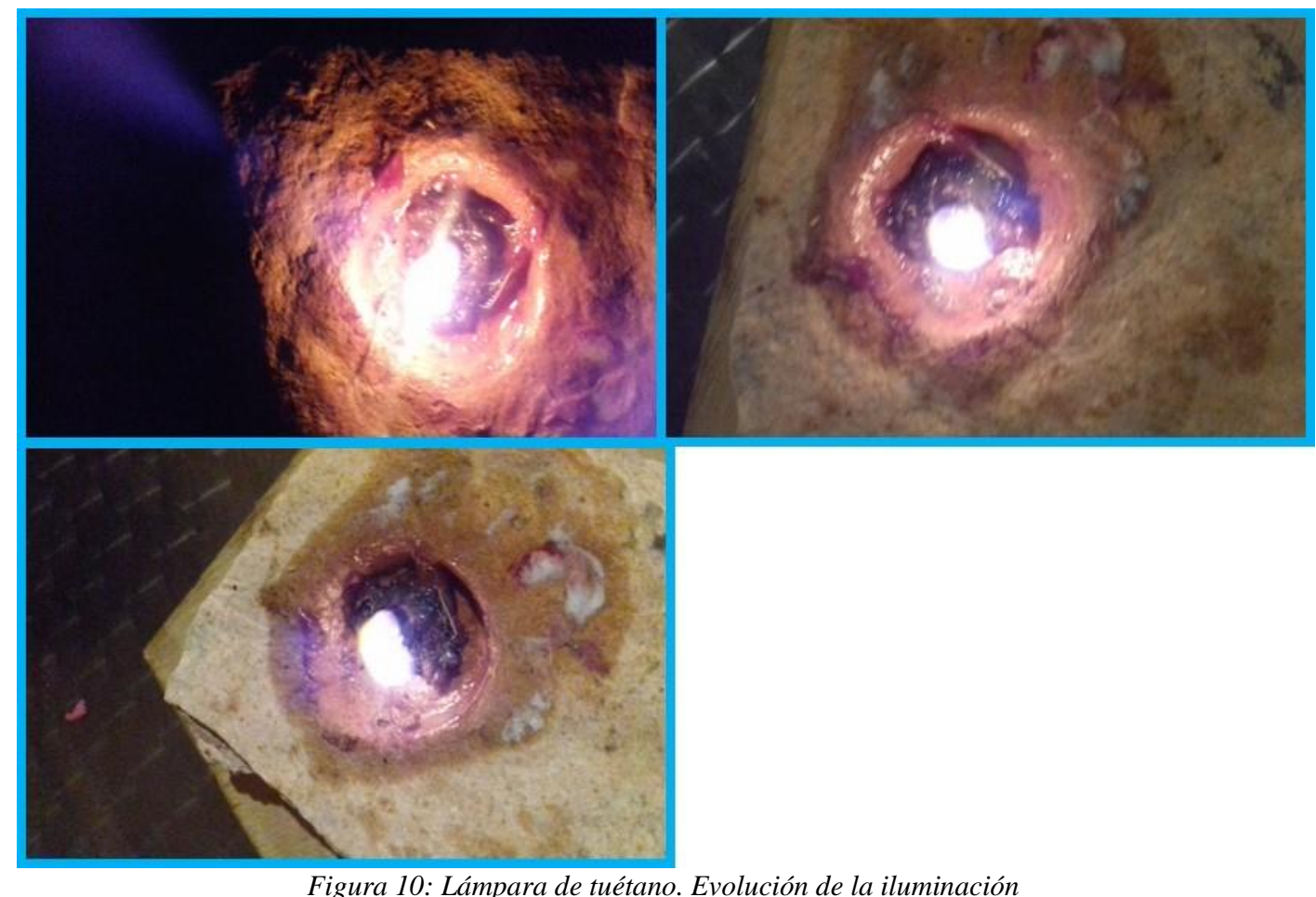

\subsection{Tercer experimento}

La lámpara de sebo al inicio del experimento da una luz más blanca con 0’15 1x de intensidad lumínica. A la hora hay una llama muy pequeña que mantiene otra media hora hasta que se apaga (Fig. 11).

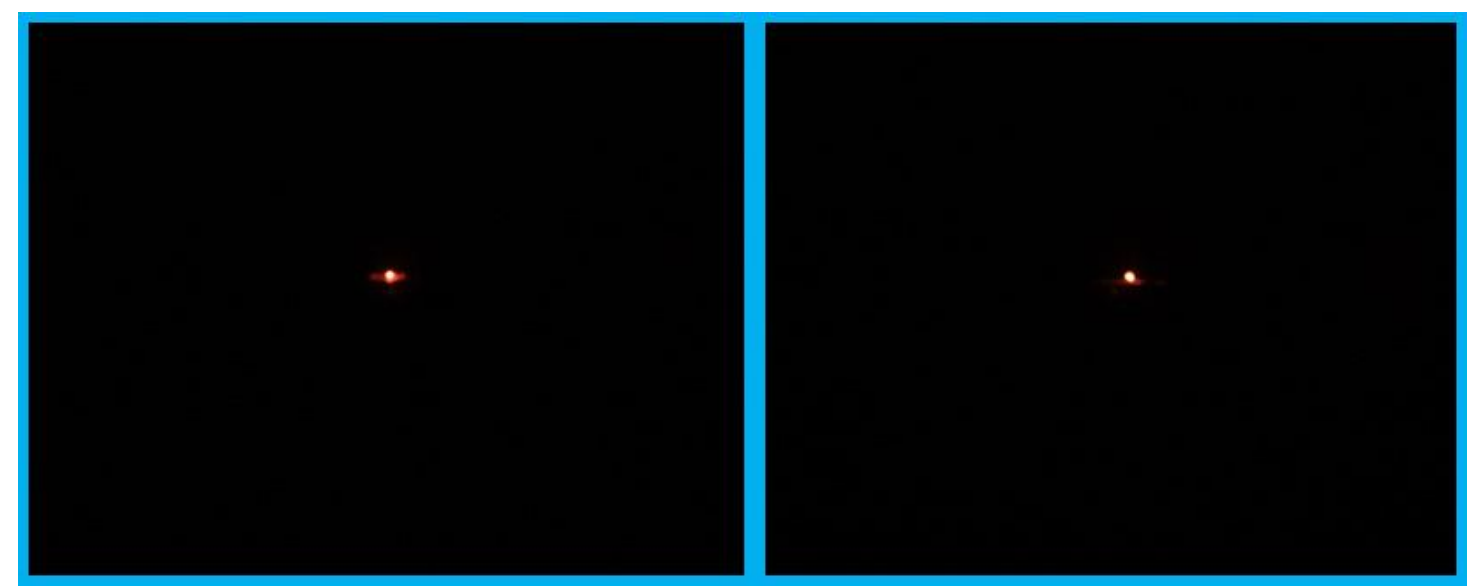

Figura 11. Lámpara de sebo. Evolución de la iluminación

\section{CONCLUSIONES}

Se deduce de esta investigación con respecto a los resultados obtenidos de luminosidad y duración, que el combustible idóneo es el tuétano, seguido de la cera de abeja y del sebo. Es necesario tener en cuenta el tipo de material empleado en la fabricación de la mecha, así como la manera de fabricación. El tuétano, al ser un elemento más graso, genera un aceite que facilita su proceso, llegando a consumir totalmente la cantidad empleada en su proceso. 
Ahora bien, además de lo expuesto anteriormente con respecto a la mecha, al no haber realizado el experimento con los otros dos combustibles (la cera y el sebo) en estado líquido, no se puede concluir si los resultados habrían sido diferentes en ese caso.

La eficacia del tuétano como combustible se ha visto favorecida, en un soporte cerrado, por la mecha y su colocación vertical, produciendo unos resultados equilibrados en luminosidad y duración de la llama, que produce una lámpara eficaz.

\section{Bibliografía}

DE BEAUNE, S. A. (2000): "Les techniques d'éclairage paléolitiques: un bilan". Paleo, 12: 19-27.

DE BEAUNE, S. A. (1987): Lampes et godets au paléolithique, Éditions du CNRS, Paris.

CASO, G. (2011): “Cueva de Ardales (Málaga): el 'Homo sapiens' utilizó cera de abeja para hacer lámparas, según su estudio". En Terrae Antiguae [Blog]: https://terraeantiqvae.com/group/prehistoria/forum/topics/cueva-de-ardales-malaga-elhomo-sapiens-utilizo-cera-de-abeja-par [Último acceso: 29/05/2019].

CANTALEJO, P., ESPEJO, M. M., RAMOS, J. y WENIGER, G. C. (2014): "Elementos de iluminación”. En RAMOS, J., WENIGER, G. C.,CANTALEJO, P. y ESPEJO, M. M. (coords.): Cueva de Ardales (Málaga). Intervenciones arqueológicas 2011-2014. Pp. 119146. Ed. Pinsapar: Benajoán.

CORTÉS, M., SIMÓN, M. D., MORALES-MUÑIZ, A., LOZANO, Mª C., VERA, J. L. y ODRIOZOLA, C. (2016): "La caverna iluminada: una singular lámpara gravetense arroja luz sobre el arte parietal de la cueva de La Pileta (Benaoján, Málaga)". Trabajos de Prehistoria, 73 (1): 115-127.

DIARIO DE LOS YACIMIENTOS DE LA SIERRA DE ATAPUERCA [Online] "Una lámpara de tuétano". En DÍEZ, C. (coord.): Origen. Cuadernos de Atapuerca. Diario de los yacimientos de la sierra de Atapuerca. Arqueología experimental, 13: 11. www.diariodeatapuerca.net/Lamparadetuetano.pdf [Último acceso 29/05/2019].

DE LA RASIlla, M., DUARTE, E., SANTAMARÍA, D., MARTÍNEZ, L., FERNÁNDEZ, J., RODRÍGUEZ, V. y FORTEA, F. (2010): “Licnología paleolítica: las lámparas de las cuevas de Llonín y el Covarón (Asturias)”. Zephyrus, LXV: 103-116

MEDINA, M.Á., CRISTO, A., ROMERO, A. y SANCHIDRIÁN, J. L. (2012): “Otro punto de luz. Iluminación estática en los 'santuarios' paleolíticos: el ejemplo de la Cueva de Nerja (Málaga, España)". En CLOTTES, J. (dir.) : L'art pléistocène dans le monde I Pleistocene art of the world / Arte pleistoceno en el mundo, Actes du Congrès IFRAO, Tarascon-sur-Ariège, septembre 2010, Symposium Art pléistocène en Europe. $\mathrm{N}^{\circ}$ spécial de Préhistoire, Art et Sociétés, Bulletin de la Société Préhistorique Ariège-Pyrénées, LXV-LXVI, 2010-2011, CD: 105-121.

PÉREZ, E., y MUÑOZ DOMÍNGUEZ, D. (2015): Los combustibles en las lámparas del Paleolítico Superior. Trabajo de curso inédito. Universidad Autónoma de Madrid. Departamento de Prehistoria y Arqueología 